\title{
Languaging Behaviour as Catalytic Process: Steps Towards a Theory of Living Language
}

[PART II]

\author{
Paul J. Thibault, \\ Faculty of Humanities, University of Agder, \\ Kristiansand, Norway \\ Faculty of Education, University of Hong Kong, \\ Hong Kong SAR, PR China
}

\section{The Specificational Character of Linguistic Information}

Linguistic information persists in the environment on the long, slow timescales of culture. Information in the Gibsonian perspective serves to regulate behaviour and, potentially, to change the animal's relationship to its environment. Moreover, information is a resource that must specify other environmental resources, as Reed (1996a: 48) points out, without being the same as those other resources. How does this apply to languaging behaviour? In Gibson's theory, information in the environment exists in structured ambient energy fields. The task of the animal is to locate the structure in such fields (Reed 1996a: 48). Information is specificational in Gibson's theory - it functions to specify particular environmental affordances. Structured ambient energy field remain invariant under certain transformations caused by the animal. Such invariants serve to specify persisting environmental resources. Information in a structured ambient energy field is a complex structuring of contrasts or differentiations caused by the ways in which an environmental event (e.g. a slamming door or a person's vocal tract activity) causes the acoustic or other medium to be restructured such that perceivers can become coupled to the source of the disturbance of the array, i.e. the environmental event.

Languaging behaviour, I suggest, makes available to both the self and others just such structured ambient energy fields. The detection of invariants in this field includes the phonologically salient contrasts created by organ-specific vocal tract gestures (Section 15). Linguistic information as discussed above specifies something about the relevant environment in which it is uttered. Information of this kind remains invariant irrespective of what particular individuals do. This is what Gibson (1986 [1979]) called exterospecific information. Gibson distinguishes this kind of information from propriospecific information, which depends upon what the organism is doing now. The latter specifies how the animal is engaging with its environment. Both kinds of information are simultaneously available in the structured ambient energy fields generated by languaging behaviour. Exterospecific linguistic information includes the information generated by predicational relations in language. It is 
information about the environment. Propriospecific information includes information generated by the bodily dynamics of languaging behaviour. It is information about how the animal's own activity regulates its behaviour in the environment. In principle, the former can be used independently of any action on the environment.

By the same token, propriospecific information can be used independently of knowledge obtained from the first kind of information (Reed 1996a: 49). Thus, languaging agents can deploy propriospecific information to orient to and explore a structured ambient energy field caused by someone's vocal tract activity without knowing the informational content in the first sense. They can apply their sensorimotor knowledge (Noë (2004: 9; Section 13) before necessarily being able to activate a content. Persons can regulate their own perceptual exploration of such structured ambient arrays by regulating their own orienting to, attending to, and engaging with the array on the basis of propriospecific information about their own languaging behaviour - both uttering/articulating and responding. Persons monitor their own and others' bodily dynamics in ways that enable them to adjust to, calibrate with, and anticipate the perceptual exploration of the many fine-grained discrimination that enable them to regulate their own languaging behaviour.

This view differs from the standard one. According to the standard view, language is stratified into different levels of expression and content. Expression is the vehicle for the encoding, transmission, and decoding of content by sender and receiver, respectively. In this view, language gets separated both from persons and from the environment, as in Halliday's 'interface' view of the relationship between the content stratum of language (semantics and lexicogrammar) and the ecosocial environment (Section 7). On the other hand, when we see that utterance-activity carries the two kinds of information identified by Gibson, we have a principled way of showing how information in this dual sense unifies organism and environment. This is so because the simultaneous presence and pick up of the two kinds of information in languaging behaviour is grounded in active, embodied agents engaging with their worlds through their language behaviour rather than formal realizations of a linguistic computational system in which different levels of formal linguistic organization provide the coded inputs and outputs to each other. The latter kind of theory has no place for the fact that languaging agents are aware of their own activity insofar as propriospecific information is available and can be detected by them (Reed 1996a: 58) as an essential aspect of languaging behaviour that requires explanation. Halliday's account is a variant on the standard account that divides semiotic processes into three kinds: input (experience of the ecosocial environment), output (bodily activity, e.g. articulation), and higher-order integration of the two (phonology and lexicogrammar as mediators and organizers of input and output).

The current approach, on the other hand, emphasises real, living languaging behaviour of persons and how they actively explore and pick up and/or make information available and how they use that information to regulate their own and others' behaviour and awareness. This stems from the fundamental insight that action and perception are not separate, but are two aspects of the same active process of exploring the world. Instead of sensory inputs from the ecosocial world that are then reconstructed by the brain as meaningful semantic 
information by a coding/realizatory process across formal levels of input/output, the ecological view sees languaging activity as a process of active exploration and detection of information that is made available in structured ambient energy fields. The task of languaging agents is to find ways of both making it available and detecting it. The task of doing so is a form of exploratory activity as agents apply what Noë called "sensorimotor knowledge" (2004: 9) in order to mediate the transitions between invariants in the processes of linguistically catalyzing their worlds.

Vocal tract behaviour of persons causes and makes available to self and to others structured ambient energy fields. These afford possibilities of information exploration and pick up. The affordances of such events constitute a complex network of interactive possibilities along many dimensions of contrast that are potentially available to perceivers in the structured ambient energy fields made available in the environment by languaging behaviour. These many and overlapping possibilities are accessible in the first instance through the application of sensorimotor knowledge and skills. The various interactive potentialities of the given utterance are therefore potentially available and accessible through the exploration of the multiple dimensions of contrasts both typological-categorial and topological-continuous. For example, one can attend to organic-specific segments while also attending to the intensity of the speaker's vocal activity. Moreover, the interactive potentialities will persist over the time frame of the utterance (Section 15).

\section{Interactivity, Learning, and Languaging}

The state space of vocal tract gestures is not a pre-constituted knowledge or system of possibilities that speakers realise, but a virtual learning space in relation to which one composes "the singular points of one's own body" in conformity to this problem space. Deleuze expands on this point with respect to his concept of the Idea, as follows:

In fact, the Idea is not the element of knowledge but that of an infinite "learning", which is of a different nature to knowledge. For learning evolves entirely in the comprehension of problems as such, in the apprehension and condensation of singularities and in the composition of ideal events and bodies. Learning to swim or learning a foreign language means composing the singular points of one's own body or one's own language with those of another shape or element, which tears us apart but also propels us into a hitherto unknown and unheard-of world of problems. To what are we dedicated if not to those problems which demand the very transformation of our body and our language? In short, representation and knowledge are modelled entirely upon propositions of consciousness which designate cases of solutions, but those propositions by themselves give a completely inaccurate notion of the instance which engenders them as cases, and which they resolve or conclude. By contrast, the Idea and "learning" express that extra-propositional or sub-representational problematic instance: the presentation of the unconscious, not the representation of consciousness.

(Deleuze 2004 [1968]: 241) 
The state space of vocal tract gestures is a state space of virtual problems that is not opposed to the real, but to the actual (Deleuze 2004 [1968]: 263). Deleuze remarks: "The only danger in all this is that the virtual could be confused with the possible. The possible is opposed to the real, the process undergone by the possible is therefore a "realisation". By contrast, the virtual is not opposed to the real; it possesses a full reality in itself. The process it undergoes is that of actualisation." (Deleuze 2004 [1968]: 263). As discussed in Sections 8 and 26, the productive differentiations that are articulated in vocal tract gestural behaviour are not the realisation of a prior set of possibilities, but the actualization of individuated solutions to the virtual problem spaces constituted by language. Interactive differentiations just are such actualized solutions (Sections 5, 8, 17, 21, and 26).

Humans learn best in situations that promote rich, culturally saturated interactivity when they engage with and manipulate external artefacts to solve learning tasks and cognitive problems in often complex environments such as aircraft cockpits (Hutchins 1995b), interpreting fMRI brain scans by brain scientists (Alač and Hutchins 2004), and medical simulations involving senior doctors and trainee doctors (Steffensen, Thibault, and Cowley 2010; see also (Hutchins 1995a, 2010; Clark 1997, 2008; Kirsch 1995a, 1995b). Interactivity and the forms of coupling of agents to their environments that it enables is not reducible to low-level perceptual-motor skills, but is central to higher-order cognitive operations in complex environments requiring expert knowledge. Moreover, a long tradition of work in experimental psychology (Koffka 1910, 1935; Luchins 1942; Vallée-Tourangeau et al 2011) shows that what Koffka (1910) identified as latente Einstellung ('latent attitude'), or experience-based predispositions to learning, can influence learning negatively and therefore can guide learning in inefficient ways that delay or frustrate desired outcomes (Kirsch 1995a; Vallée-Tourangeau et al 2011).

Building on Koffka's insight, the experimental works of Luchins (1942) and ValléeTourangeau et al (2011 indicate the potential of interactivity to diminish negative predispositions towards learning. Unlike learning based on text-based models or mental simulation inside the individual's head, a rich, dynamical multimodal environment consisting of manipulable artefacts affords a changing array of affordances and possibilities of perception and action. These affordances and possibilities attract and shape attention and action. In doing so, they constrain action, knowledge and cognition in ways that seem more likely to promote positive learning experiences and outcomes. Interactivity with persons, artefacts, tools, and technologies in the physical and cultural environment enables learners to segment and identify the features of that environment so that they develop more effective learning strategies. Interactivity through visual scanning, haptic manipulation and exploration, sound, and movement enables learners to manipulate and re-organize the physical aspects of the learning task such that active exploration and manipulation of physical artefacts gives rise to new perceptions and new differentiations. In turn, these can transform the learning task.

These findings have important implications for the virtual forms of interactivity made possible by languaging. Generally speaking, languaging agents use the action-perception possibilities of their bodies to interact with aspects of their environments in ways that augment and enhance differentiation and therefore learning and cognition. Interacting with the 
virtual environment constituted by second-order cultural patterns is an extension of this basic fact of human cognition. First-order interactivity is based on the exploration and detection of visual, spatial, kinesic, tactile, and other modes of action-perception. First-order languaging provides a rich, dynamic multimodal environment that both extends participants' grounding in the familiar physical world and makes available new kinds of manipulable perceptual input grounded in virtual worlds. Interactivity takes place in a richly multimodal interactive environment. This environment draws persons' attention to the features of problems that may help them to adopt more effective learning strategies. First-order interactivity enables agents to manipulate and restructure the nature of cognitive tasks. The cognitive task becomes a changing, dynamical multimodal configuration that reveals new affordances during the agent's time-bound interactions with the task.

The cognitive environment and thus the appeal of this kind of richly multimodal environment to many people, I hypothesise, is 'richer' and more 'intuitive' than text-based technologies and practices because it affords the manipulation and reshaping of the cognitive task through very natural, intuitive activities of our bodies such as touching, moving, pointing, visual scanning, talking, and auditory prompts and cues of various kinds (Hutchins (1995a, 1995b, 2010; Kirsch 1995a, 1995b; Clark 1997, 2008; Wilson and Clark 2009; Vallée-Tourangeau 2011). In other words, languaging is grounded in and extends the natural interactivity of human bodies. Multimodal action-perception cycles and their integration though interactivity mean that socially coordinated languaging can transform the presentation and representation of the on-line learning task in ways that regulate and shape learners' attention, perception, and cognition. These processes are based on interactive differentiation rather than the encoding of transduced inputs. Differentiation arises as a result of active exploration; differentiations are not givens and forms of interactivity that are adequate to the task of yielding such differentiations must be devised. Rather than the rlepresentation of an already settled reality by discursive modeling, interactivity couples persons to matter-energy flows and material practices so as to influence and guide them as well as to discover new things about them. This avoids the conservative essentialism whereby discourse-analytical approaches, for example, reduce everything to man-made categories of mind. The far more unruly material reality on diverse scales and their histories cannot be settled in this way. Interactivity is more concerned with intervening experimentally in the material world and seeing how it responds rather than the discursive modeling of realities already assumed to be settled in advance by the linguistic and other formalisms of the human mind and their conventions.

\section{The Feel of Languaging Events: Value-weighted Dynamics}

As we saw in Section 9, languaging agents exploit timing to register the value-weighted significance of visible, audible and sensible patterns in pico-scale events. They register in core consciousness the differentiated feel of such events and, drawing on a history of their participation in language practices, they produce a response based on a sense of felt agency in relation to the resulting 'feeling of knowing' (Damasio 2010: 209). That is, agents perceive that a given behaviour and its dynamical properties have an evaluative significance that has the functional capacity to influence the behaviour of self and others. How this influence 
works depends on both the physical properties of the vocalization or other gesture and the perspectives on it that are adopted by speakers, listeners, and observers of such events in the dialogical array. Values in turn may be associated with particular sets of circumstances in the life of the individuals concerned. Far from being arbitrary, the acoustic and other dynamical properties of vocalizations are structured in ways that orient the attention, arousal, and motivation of listener-observers owing to the direct links between the auditory periphery and brain stem regions regulating whole-body arousal, feeling states, and action (Section 4). The dynamical bio-physical properties of vocalizations elicit immediate, whole-body responses on many different scales of organismic organization which are functional in responding to and managing different types of situations.

Prosody can be affectively and intentionally modulated to these ends. The question arises as to how prosody and responses to particular dynamical (acoustical and other) properties of different kinds of prosody in vocalizations can provide critical scaffolding for learning about different kinds of situations. This is so because the links of the auditory periphery to brainstem regions having to do with affect, arousal, and motivation also link directly to the amygdala and hippocampus (LeDoux 1996, 2000). Hence, different bio-physical properties of vocalizations may help infants to learn about particular kinds of situations and to remember the details of the action scripts that are called forth by these situations. The bio-physical properties of vocal events act directly on the neural-hormonal, perceptual, affective, and learning systems of listener-observers in ways that enhance adaptive, flexible behaviour and its development. The expressive bodily dynamics of languaging agents do not so much express or reveal the inner feelings of agents; instead, the dynamical properties of vocal, facial and other bodily expression have the capacity to induce feelings in self and others (Laird 2007).

Laird (2007: 13) uses the example of a smile to show this: a feeling of happiness is not directly caused by the smile, "but [is] rather a product of the relationship between the smile and the context in which it occurs." (Laird 2007: 13). The feeling of happiness is therefore an evaluator of the situation in core consciousness. The smile is part of a socially displayed emotion script that serves to co-regulate agents' relationships to aspects of their worlds that are made salient by the relationship between the feeling in core consciousness, the smile, and the situation. The smile is part of the coordinated dynamics of inter-individual interaction behaviour; it enables persons to see aspects of situations in value-weighted ways according to the perspectives that are triggered when the protoself in core consciousness is perturbed by the coordinated dynamics of such behaviour (Section 11). Languaging dynamics accordingly partition the world in ways that pave for way for the emergence of compressed possibility spaces, i.e. digital semantics, in symbolic neural space.

People make us of the dynamics of vocal, gestural and other forms of bodily expression or first-order languaging behaviour to coordinate perspectives and to move people - affectively, cognitively, and interactively -- in ways that are increasingly decoupled from on-line perception (Deacon 1996). Individuals respond to these dynamical properties of such events. In learning to do so, they engage in meta-linguistic practices that draw attention to aspects of 
the dynamics, i.e. wordings, (Cowley 2008: 339) and how these are or may be integrated with a cultural universe of virtual entities that are evoked by lexicogrammar qua second-order cultural patterns (Thibault 2011) and which afford 'mental time travel' (Corballis 2011: 100111). These practices put the emphasis on the primacy of interactional history and also on how the relevant brain structures evolved as adaptations for coordinated, inter-individual firstorder languaging, rather than on abstract, disembodied systems that are said to process linguistic forms in the brain/mind or in text/discourse, as in mainstream formal, functionalist, and cognitive accounts of language. The question then becomes: how do individuals integrate wordings with bodily dynamics? In first-order languaging events, individuals attend to how aspects of the dynamics can be integrated to locally salient cultural meanings and values. The dynamics modulate wordings and bind them together into locally coherent units of embodied sense-making at the same time that the dynamics are constrained by wordings.

Dynamics have intrinsically unstable properties that set "the brain onto an itinerant trajectory, that is, a pathway through a chain of preferred states, which are learned basins of attraction." (Freeman 2000: 121). The hearing of wordings in the dynamics constitutes a local, momentary capture of aspects of the dynamics by a basin of attraction, thus providing an awareness of semantic closure. Our experience of the dynamics of languaging behaviour is a consequence of our time-bound exploration of the sensorimotor contingencies of the dynamical properties of utterances and of our assimilation of these properties to basins of attraction that enable us to experience wordings. Wordings qua lexicogrammatical forms cannot be directly 'decoded' from they dynamics; they were never 'encoded' into them in the first place. Freeman (2000: 120) shows how the brain learns about environmental events by organizing the dynamical properties of the brain and the body in ways that make them similar to the event that is encountered (Sections 14, 21).

As Gibson (1986 [1979]), Reed (1996a, 1996b), Hodges (2007), and other ecological psychologists have shown, persons actively explore environmental events and in the process of exploring them, they can change their perceptions of them. This does not mean that the event imprints its own features on the brain. We experience words in dynamical speech events not as features that are encoded in these events and which then impress themselves upon our bodies and brains in a passive decoding process. Instead, through repeated, habitual yet active participation in action-perception cycles, our perception of events is educated such that the sensory receptors are positioned though efference and the sensory cortices through preafference (Freeman 2000: 121). In other words, we learn actively to attend to such events and their dynamical properties so as to achieve an "optimal assimilation of the self to the object." (Freeman 2000: 121). In this explanation, there is no requirement that neurons decipher and decode perceived events. Davia comments on the alternative suggestion as follows:

It suggests instead that the significance of a given neural event is that it occurs at a certain place and at a certain time within an overall context of neural events taking place in space and time. It is the direct correspondence between the relative position and timing of events in the perceptual field and the brain that is of primary importance. 
Indeed, there is a direct topological mapping between the retina and the V1 layer in the visual cortex. What this means is that a triangle in the visual field, for example, translates to a triangle of neural excitability and/or suppression in the V1 layer. The relative spatial and temporal relationships implicit in the triangle are preserved in terms of how the medium is structured.

(Davia 2006: 278)

and

Because the suggested mechanism of brain processing is the soliton (or travelling wave), the relationship between soliton formation and the structure (invariance or symmetry) of the environment may offer an insight into how the brain unifies aspects of the environmental stimulus into the familiar objects and events of perception. For an object or event to become an object of cognition it must embody invariance or symmetries, what is being called "structure", in space and/or time. If the potential object or event of perception embodies structure, then via the senses, that structure translates to excitable areas in the brain that embody invariance or symmetries in space and/or time. Travelling waves in the brain sustain themselves by releasing this energy, hence, they constitute a process of catalytic mediation. Thus, the particular solitonic or travelling-wave solution is dependent upon the structure (invariance, symmetry) of the objects or events of perception.

(Davia 2006: 278)

The symmetries and invariances of vocal tract gestures qua environmental events structure the acoustic medium; they depend upon the symmetries and invariances within the medium and its boundary conditions (Davia 2006: 280). As Davia argues, this gives rise to a soliton-like travelling wave solution to the problem of the implicit order in the event that is encountered:

It may seem that what is proposed is that travelling waves progress through the brain in much the same way as they progress through an excitable medium. This is not the case. As was mentioned previously, we can choose to observe a soliton such that the soliton remains in a fixed position, maintaining its organization, while mediating a set of transitions. The brain is posed with a similar problem. Whatever neural activity corresponds to the perception of an event, it must maintain its integrity, given the set of transformations in space and time imposed upon the brain as a consequence of the transformations in space and time embodied by the stimulus. As Gibson [24] and other perception psychologists have emphasized, we should think of the act of perception as dynamic, not static. There is a constant stream of stimuli, much like the constant stream of water moving through the soliton in the canal, and the essential geometric and temporal relations are preserved as an aspect of neural activity.

To illustrate this point, we can visualize a simplification of a "data stream" imposed upon the visual cortex by a triangular stimulus, schematically depicted in Figure 2. If 
we imagine the situation of a child who is too young to recognize a triangle, the same set of transformations is imposed upon the visual cortex as in the case of an older child who is able to recognize the triangle.

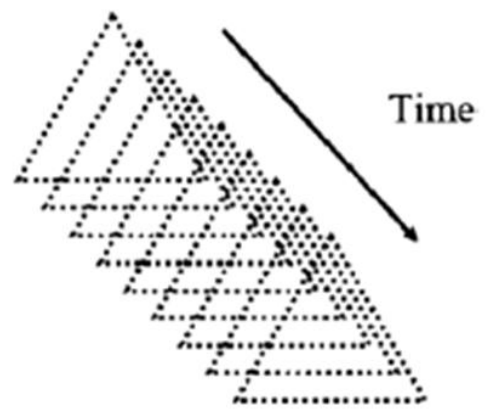

Figure 2: A simplified representation of the data stream in the visual cortex as a result of looking at a triangle

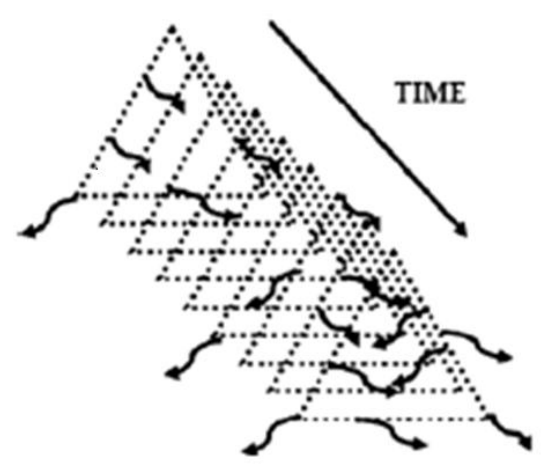

Figure 3: A simplified representation of activity in the visual cortex of a child who is too young to recognize a triangle

However, the energy that is released as a result of the stimulus disperses in a chaotic way (see Figure 3). Feedback relationships among neurons that fire as a consequence of stimulus may be formed momentarily among aspects of the triangle and other objects in the visual field. These cannot be sustained, however, because there is no ordered relationship among these different stimuli; there are no invariants or symmetries. They may be moving quite randomly with respect to one another, and so any relationships that may be formed quickly become unstable. However, solitons or travelling-wave solutions depend upon symmetries or invariance within the medium and its boundary conditions. It is the order that is implicit in the stimulus, the symmetries or invariance, that facilitates the emergence of travelling-wave solutions.

(Davia 2006: 279-280)

Solitons can maintain their organization while mediating a set of transitions. The two parity constraints identified by Fowler (2010) - i.e. (1) phonetic gestures are public events and (2) they persist in time (Section 15) - are important here. As we saw in Section 14, languaging agents manufacture a robust semantic synthesis - a stable semantic artefact - when they are 
able to unify the spatiotemporal invariances of the soliton-like waves of languaging behaviour with relevant covarying aspects of situations, prior experience of and a past history of participating in such events, intentions, socio-cultural norms and values, and the relevant higher-scalar boundary conditions. Second-order cultural constructs such as lexicogrammar are boundary conditions in this sense. The travelling waves of languaging behaviour can thus maintain their organization at the same time that they mediate a set of transitions in their environment. Davia (2006: 281) explains that this is so because a soliton is "always continuous with its boundary conditions." It is always completely integrable to and constitutes a solution to its boundary conditions.

In Halliday's (2004) account of the relationship between language and the individual person's experience of the ecosocial environment (Section 7), it is somehow assumed in ways not made very clear that there exists a world of ecosocial experience with which the semantics of language 'interfaces' and reorganizes through lexicogrammar as the semantic categories of our experience. But this is a bit like putting the cart before the horse: we must first analyse the dynamical properties of vocal tract gestural events and the ways in which they both dynamically structure their environments and the awareness of languaging agents. The basic problem is the deeply rooted assumption that there just is a world out there that language interfaces with and in some way 'represents', 'encodes' or 'transduces' into the categories of language. A different theoretical solution is provided by Davia's (2006: 281-283) distinction between cognition as representation and cognition as ontology. Davia explains this with the example of a mountain:

... we often take for granted aspects of the world revealed to us by our minds as being meaningful beyond the world of perception. For example, we have no doubt that a mountain exists whether we are looking at it or not. Although trivially true, this basic assumption must be critically examined. Exactly what do we mean by the statement that "A mountain exists"? Although there is a collection of implicit invariant relationships in space and time in the overall arrangement of rock strata, boulders, and stones, and molecules, etc., there is nothing that unifies the mountain in terms of those implicit relations and invariances. The mountain, then, is only implicit in a set of geometric invariances in space and time.

(Davia 2006: 281)

In similar fashion, vocal tract gestures of speakers are presented to the perceptual systems of prospective listeners as discrete, discontinuous events. A linguistic utterance qua semantic synthesis (Section 14) is only implicit in such events when persons encounter them in their worlds. There is no pre-given linguistic object that is presented to the brain of the listener. The given linguistic object, following Davia, is only implicit in a discrete, non-unified set of statistical invariances. The vocal tract event as it occurs in its environment is a discontinuous set of spatiotemporal events. It is the neural activity corresponding to the active perceptual exploration of the sensorimotor contingencies of the event that unifies the multidimensional invariances of the co-articulated vocal tract event, i.e. the set of spatiotemporal symmetries that the event embodies implicitly (see Davia 2006: 281), into a single, unified dynamic - a 
soliton-like travelling wave. The wave, as Davia points out, "is not a representation, but an ontological phenomenon." (2006: 281). The ontology of a vocal tract event in its environment may include organ-specific gestural contrasts, a pattern of wordings that are perceived in those contrasts, rhythmic, tonal, and other properties.

Moreover, the ontology of linguistic events may also include the implicit underlying representational topologies that such events can activate, the apperception of prior events with which similar events covaried in the person's experience, relevant covarying aspects of situations and situation conventions and their associated reflexivities, cultural norms and values, and so on. In far more complex ways than the mountain and the triangle in Davia's (2006: 2810282) examples, the behaviour of a vocal tract gestural event, its implicit discontinuous spatiotemporal invariances, give rise to emergent macroscopic behaviour that may appear to be intrinsic properties of the vocal tract event itself. However, vocal tract events do not constitute a continuous unified dynamic whose form and behaviour is a result of its own unified dynamics. Instead, our active perceptual exploration of such events gives rise to soliton-like travelling waves in the brain that correspond to (not represent) the event and which exhibit the same ontology as the event (Davia 2006: 282).

... in this case, that ontology would be a direct result of its unified internal dynamics, a continuous solution to the boundary conditions imposed upon the excitable medium of the brain as a consequence of stimulus that embodies the ontology implicitly. Thus, perception makes explicit the implicit ontology of the objects and phenomena of the world around us.

(Davia 2006: 282)

When we experience a vocal tract gestural event, we don't under normal circumstances perceive individual features per se, e.g. organ-specific gestures, but the dynamical relations among the many potential dimensions of contrast (the invariances and symmetries) in the event along with the fragments of other previously experienced events recalled in rich phonetic memory. This active, structuring process centrally includes awareness as a necessary component for the structuring of intelligent behaviour (Freeman 2000: 121) through the skilled application of sensorimotor knowledge. This is a necessary step if we are to explain the relationship between the phenomenological (qualitative) aspects of our conscious experience of languaging events and the quantitative dimension (the statistical invariances and symmetries) of such events. Davia's solution is that we correlate conscious experience with the "dynamic and relational properties of nonlinear travelling waves" (2006: 282) as we engage in the active perceptual exploration of these properties. The travelling ways generated by languaging agents compress (see Sections 4, 6, 12, 21, 24), informationally speaking, potentially many dimensions of implicit order deriving from very diverse and heterogeneous time-scales ranging from the cultural-historical to the here-\&-now (Lemke 2000b) (See also the discussion of fractal patterns in Section 6).

The persistence in a population of languaging agents of the implicit order - the patterns, symmetries, invariances - of vocal tract and other related gestural or articulatory events are 
the affordances that create the necessary conditions for the creation of soliton-like in the brains of these same agents. The robustness of the resulting semantic artefacts that are catalyzed during linguistic cognition between agents is a consequence of the way in which such artefacts and their forms of cognition make explicit the implicit order of the culturalcognitive environment that they mediate as part of the process of linguistic catalysis. The dynamics of nonlinear, soliton-like waves, e.g. in vocal tract activity, persist in the culturalcognitive environment by uniting energy and structure. On cultural timescales, a population evolves dynamical solutions to the perceptual problems that are posed by regular, repeated occurrences of such events. Persistent patterns of this kind mean that neural wiring in a population will ensure the emergence of a similar dynamic when prompted by the same kind of stimulus (Davia 2006: 283). This means that the brain will metabolize a new cognitive state according to the linguistic stimulus. On the basis of statistical learning (Kuhl 2007) in a population of languaging agents, infants learn to attune to the implicit order of the dynamical properties of habitually repeated first-order languaging events in their environment such that a travelling wave dynamic emerges in the brain that unities and synthesizes the diverse elements into a unified perceptual object.

Meaning is not the result of an encoding/decoding process. The emergence of a unified dynamic makes explicit the differentiating or discriminatory potential of vocal tract events along potentially many dimensions of contrast (both typological-categorial and topologicalcontinuous). Making explicit a particular pattern of differentiations means that this pattern has the functional capacity to operate on and to evoke implicit representational topologies consisting of both individual and social dimensions of a prior history of covariance relations between perceived patterns of differentiations in vocal tract gestures and environmental events. The perception of a particular wording in a particular pattern of pico-scale dynamical properties in utterance-activity would be an example of how invariances are made explicit. Meaning is catalyzed when the nonlinear dynamic of a soliton-like wave makes explicit the invariances - individual, social, and cultural - in the relationship between a vocal tract gestural event and the environmental phenomena from different space and time-scales with which the event is synthesized to form a thermodynamically more stable semantic artefact (Section 14). Davia (2006: 285) relevantly points out: "Meaning is the experience that we have when that implicit ontology becomes explicit." Semantic artefacts themselves have the capacity to persist in a population as conventionalized typifications that constitute normative solutions to problems of both individual and social coordination and cognition. The catalyzing of a semantic artefact has the further functional capacity to catalyze flows of (self)-awareness, perception, cognition, feeling, affect, and action in individuals and groups, including virtual modes of experience (Verbrugge 1980: 94; Thibault 2011: 221). Lexicogrammatical patterns both stabilize and intermediate the pico-scale neural and bodily dynamics of individuals, on the one hand, and the macro-scale dynamics of society and culture, on the other.

The emphasis on affect, value-weightings and timing, rather than on form-based models of symbol processing as, for example, in discourse-analytical approaches, helps to advance our understanding of why we experience some behaviours as intelligent, meaningful and motivated (Section 4). If we take the full-bodied languaging agent as our locus rather than the 
abstract, de-somatised forms typically focused on in the linguistic description of verbal patterns, we see more clearly that what matters is not so much how we interpret behaviour symbolically, but how flexibility enhances cognition, seen as an essential process of the living, embodied organism embedded in and coupled to its world. Organisms draw upon a history of multiple constraints on many different spatial and temporal scales to develop ways of regulating both themselves and others in order to benefit both the individual and the group. Actions and decisions make use of values both within the organism and in the environment to achieve homeostatic self-regulation (Damasio 2005). A focus on the processing of abstract symbolic forms remains an externalist perspective on the organism-environment relation (Maturana and Varela 1980, 1987).

As these researchers have pointed out, an externalist perspective tends to obfuscate living cognitive processes by defining them in terms of the functions that they perform - functions that are realized by abstract symbolic forms (Section 8). The expressive dynamics of living, feeling, moving bodies are thus seen as no more than the physical means of supporting and implementing these higher-order functions such that bodily dynamics and the cognitive and expressive powers of the body are downplayed or ignored. In this way, the specific characteristics of bodily dynamics and the central role they play in languaging behaviour and the cognitive and affective processes that these enact remain unappreciated and unexplained (Thibault 2011; Section 4). Language is a catalytic process grounded in agents' sensori-motor couplings to and perceptual explorations of aspects of their worlds. The cognitive and affective capacities that languaging behaviour installs in agents and in collectives are not one of a progressive ascent to higher-order symbolic capacities from lower-order embodied ones.

Instead, it a process of progressive differentiation and augmentation of sensori-motor coupling capacities to the exploration of and coupling to virtual cultural entities whose digitalized semantic content is based on the objective statistical properties of a population of interacting agents, but which a network of neurons can transform into a subjectively experienced semantic category that has the capacity to affect and orient the behaviour of agents towards entities that resemble those in the learning sample. Vertical coupling of the population-level dynamics to individual person-to-person acts of linguistic catalysis ensures that an increase in the intensity of a certain kind of bottom-up interaction may alter the population-level dynamics and therefore the balance of the higher-scalar (e.g. cultural) constraints acting on these lower-scalar interactions (Van Orden and Holden 2002: 95). Changes in the population dynamics and changes in the dynamics of real-time interactions between agents are intrinsically coupled. As Van Orden and Holden point out, "Control parameters index emergent, self-perpetuating, abstract relations among individuals and groups of individuals.” (2002: 95). Virtual patterns of cultural (e.g. lexicogrammatical) constraints come into and go out of existence according to shifts in the overall balance of constraints across the vertical coupling relations involved.

\section{Lexicogrammar as Virtual Cultural Pattern}

Children often engage in bodily-based forms of intersubjective co-engagement that are scaffolded by mimetic capacities (Hutto 2008: 167; Zlatev 2008). Mimetic acts constitute and 
enact intersubjective engagement based on joint perception-action such that a shared world is created in imagination. Infants exploit shared 'mimetic schemas' (Zlatev 2008) that serve as the basis of their coordinated engagement with each other. Thus actions performed on familiar body parts and environmental objects are a part of our everyday, familiar embodied ways of acting and being in the world. These body parts and environmental objects function as intersubjective anchors (Zlatev 2008). They afford non-arbitrary connections to a range of activities and modes of display that are the focus of joint attention. Such mimetic activities constitute a means of creating objects of shared attention even in the absence of the given event or object. Mimetic activities accordingly evoke absent objects and events on the basis of potentially shareable networks of sensori-motor associations that are held in working memory.

Infants learn in time to control bodily dynamics, including vocalizing, in ways that control perceptual input. Initially, the infant has little control over this input, sending random commands to the muscles. In time, he or she learns to correlate certain random commands with specific responses in the world, especially responses from other persons. This correlation is established on the basis of the consistencies that are established between the motor command and the perceptual input. In time, the infant can elicit desired responses in others by calling up the appropriate motor command (e.g. proto-imperatives; see Halliday (1975)). He or she can control vocal and other bodily behaviours in concert with others (and later solo) that establish a consensual domain of consistent motor-sensory relationships. These motorsensory relationships bias perception in value-weighted ways that lead to higher-order behavioural control. Thus, control of vocal tract and other gestural activity mean that the gesture can be used to get others to fulfil one's needs and wants. The use of the gesture for higher-order control of this kind just is, from the child's point of view, the meaning of the gesture.

By the same token, the child learner also discovers that others in the same cultural milieu interpret his gestures on the basis of their beliefs, including beliefs concerning behavioural regularities or patterns that are shared and to which the participants are entrained. Moreover, the child discovers not only that such regularities - e.g. a syllabic pattern - can be harnessed to control his interactions with others, but that the use of such patterns is rewarded with positive affect from others. Initially, the child's gestures were directed to obtaining desirable input and avoiding undesirable input. The seeking of desirable input and the avoiding of undesirable input means that the behaviour is motivated - at first by what Trevarthen (1992, 1998) and Cowley (2008: 339-340) have discussed as the infant's intrinsic motivation system. However, the child's discovery that others use certain regular and preferred behavioural patterns in order to manage their interactions with each other in time gives the child the cultural motivation to align his or her own internal and behavioural dynamics with the dynamics of others in the same cultural matrix.

In this way, the child learns that such behavioural regularities based, in the first instance, on higher-order physical invariants (Section 10) serve as normative standards which people aim for and which they use as a reference point for evaluating their own and others' behaviours, in 
the process learning how the syllabic or other pattern is grounded in a cultural matrix of dialogically coordinated bodily activity. It is not a matter of the syllabic or other pattern encoding a meaning, but of how the pattern is integrated with other aspects of interactional events across place and time scales. This integration occurs on the basis of local cultural beliefs and values that give rise to increasingly conventionalised patterns that serve to solve problems of coordination between individuals in their social encounters with each other. The increasing ability to reify and therefore to lift out of the flow of activity some patterns (e.g. the syllabic patterns and their combinations that the child later learns to call 'words' and, eventually, to write them) and to use these patterns to control events across an increasing diversity of space and time scales may foster the illusion that these patterns are arbitrary instantiations of symbolic tokens from a language-code (Sections 3-4). But this view loses sight of the bigger picture.

Such patterns are grounded in apperception in our neural and bodily dynamics: they have the power to induce an apperception of previously experienced (and remembered) events with which the vocal, facial, or other pattern covaried (Verbrugge 1980: 94). Statistical learning is relevant here too. Infants sensitize to the distributional patterns in a given population of (aspects of) vocalizations, gaze vectors, pointing, and the specific event types with which these covary in the situations in which they are embedded. It is in this way that infants learn how language structure attunes them to virtual experience. The emergence of predication as a semantic relation between combinations of words meant that word choice was no longer dependent on the indexical association between word and extra-linguistic experience (Harris 1991). This meant that the predication had meaning by virtue of the word co-occurrence relations in the absence of correlated real-world events (Harris 1991: 354). Grammar emerges as a system of required constraints on these co-occurrence relations.

Words contain physical information about the other words with which they are likely to cooccur. Thus, the meaning of one word could predicate about the meaning of another word in ways that were de-coupled from on-line perception and experience. In this way, operatorargument structures can predicate of and confer structure upon virtual, off-line perceptions that serve to partition some aspect of virtual experience and to orient us in a cultural world of virtual things and events that are salient and important in a given population of agents. Virtual entities of this kind are grounded in stable patterns of neuronal activity whose content is a prototype that agents extract from a population of similar entities experienced by the agent. Their virtual content is grounded in the objective statistical properties of a population -properties that the network of neurons can activate as a category that is experienced as an offline virtual structure whose patterns of neuronal activation are de-coupled from on-line perception. These virtual semantic entities have the functional capacity to affect how the agent behaves towards entities that approximate the prototype that has been learned. Moreover, wordings are grounded in and constrained by the functional character of the nonlinguistic action systems from which they arise and which they never entirely transcend.

The experience of hearing wordings or lexicogrammatical patterns in languaging events only arises as a result of the agent's participation in the cultural activities that promote a belief in 
and the capacity to adopt a 'language stance' (Cowley et al 2004; Cowley 2011) on such events as the child's languaging activity comes under more and more layers of historicalcultural constraints that afford access to virtual cultural patterns. The experience of hearing wordings in dynamical language events only arises after participation in the cultural routines that promote and reward this kind of experience in the early years of the child's life. Wordings are highly abstract, compressed patterns that are implicit in the patterns of physical energy of phonetic events at very high levels of organization and knowing. The perceptual exploration of linguistic events therefore allows for the exploration of and access to increasingly abstract, virtual patterns that are nonetheless grounded in real-time bodily dynamics of languaging behaviour and can be heard in them by those who have learned the cultural tricks for recognizing and attending to them.

Cowley (2008: 340) demonstrated that our metalinguistic practices guide us to seek out words as what we think we hear in vocal activity. For instance, mothers prompt infants to repeat the words that they (mothers) believe to have a reality that is separate from the material dynamics of first-order languaging behaviour. Infants are induced to repeat the verbal pattern qua word and to ignore the behavioural flow of facial, vocal and bodily expression in which this pattern is embedded. The infant is thus made aware of words as reified verbal patterns which can be at least partially abstracted from the behavioural flux and which can be repeated and transcribed into a written notation as if they were the same replicable entities from occasion to occasion, irrespective of the unrepeatable and unique dynamical characteristics of every vocalization qua historical singularity. This reification of verbal patterns leads to the idea that meanings are transmitted from one person to another and that they exist independently of the behavioural and experiential flux of coordinated inter-individual languaging activity.

However, the flow of behaviour in such activity does not encode and transmit ideas or information from a sender to a receiver by means of words. Words and wordings, as we learn to articulate and to attend to them in languaging behaviour, are value-weighted constraints on that behaviour that bias and shape action and perception around digital semantic categories; they are not coded messages that are sent and received. Rather, a person's vocalization, for instance, makes available information that perceivers in the relevant dialogical array can attend to and extract from the vocalization through their participation in the relevant language practices and associated beliefs. The caregiver (e.g. mother, father) makes the infant aware of the verbal patterns by guiding the infant's attention to those patterns rather than others in vocal dynamics and thereby helps the infant to learn how to use these patterns to achieve higher-order control of actions (Thibault 2011). From the rich array of auditory information that is potentially available in the vocalizations that the infant hears, he or she is encouraged by caregivers to attend to those higher-order acoustic invariant patterns that, according to western cultural beliefs, specify words.

In the process, the infant also learns that the metalinguistic practices of talking about and recognizing reified verbal patterns (e.g. words and wordings) as having an independent existence and the language that is so talked about are inextricably intertwined. Thus, infants are taught how to attend to and to interact with some of the information in the auditory signal 
in order to detect and make use of verbal patterns while disattending to other aspects of the dynamics or relegating them to the background of their awareness. It is on the basis of this folk theory of wordings - Harris (1981) has called it the 'language myth' - that our western notion of verbal patterns (words, etc.) as freestanding entities constituting a code of formmeaning correlations is based. The problem with the code view is that language is treated as a second-order system of invariant forms or structures that can be isolated from the behavioural flux rather than a heterogeneity of interacting populations of dynamical events spread across different time scales of neural, bodily, interactional, and cultural processes.

\section{Virtual Lexicogrammatical Patterns as Productive Differentiators}

Utterances have intentional semantic contents that constrain the possibilities for action, perception, and cognition in particular situations. Semantic differentiators set boundary conditions on behaviour that limit the possibilities for behaviour of participants. Intentional semantic contents self-organize on cultural-historical timescales, which means that in a population of persons they persist in time relative to and are available to control processes in real-time interaction. Intentional contents thus have the functional capacity to reduce degrees of freedom in real-time interaction between persons. Semantic differentiators qua intentional contents have the capacity to effect a qualitative shift from one stable state to another in a system close to one of its critical states (Hollis et al 2009: 217); Section 9). They modify the system's phase space and limit the number of potential trajectories through that space.

According to assemblage theory, an assemblage, in accordance with our understandings of nonlinear, far-from-equilibrium systems, is an emergent dynamical system that exerts causal powers over its component parts. Semantic differentiators, in selecting and delimiting some region of socially organized matter-energy flows and states, set boundaries and restrict the options for action, perception, affection, and cognition. Participants' responses self-organize as multimodal flows of events within the boundaries set by the differentiation This capacity for sustaining the trajectory of the intention in such performances emerges within a control hierarchy of vertically coupled constraints (Van Orden and Holden 2002: 95-96).

It is commonplace to claim that language conveys information. This notion of information is very vague and ill-defined and seems to rest on the idea that the amount of information conveyed by an utterance depends on the amount of linguistic content (e.g. content words) that are packed into a given sentence ('the more content words, the more information'). Let us try and think of it in different terms. I'll start with a made up (invented) example for the purposes of a little Gedankenexperiment: You can come in now. Obviously, this sentence could be uttered in very many different situations. At first glance, this invented example is understandably difficult to understand: what is the meaning of you, what is the situation in which it is spoken, what are the respective spatial perspectives and locations of speaker and listener, who speaks and to whom, when was it spoken, and so what is the meaning of now?

We do not know the answers to any of these questions. In order to understand the utterance, we would need to know all of these factors. However, the sentence is very interesting in a nontrivial way: it already constrains for us possible situations in which it might occur and which we can easily imagine. This fact says something fundamental about the nature of 
language. We need to see language-in-action as guided by our perceptions and understandings of the events in which languaging activity is embedded. This means that we need to connect our perceptions of language structure to our perceptions of unfolding event structures, including spatial and temporal relations. I would suggest that even our invented example above shows us how language structure constrains and attunes our perceptions and understandings of the events with which language is connected.

I would argue that the 'information' in the sentence is specificational in Gibson's (1986 [1979]) sense. The utterance does not construe or encode a content that is already there. Instead, the catalytical potentiality of the utterance qua bodily event acts on and transforms the addressee's body's potential for action. The utterance does this by differentiating (not representing) and focusing on that aspect of the virtual totality of the situation that the speaker wishes to transform through the interaction into an actuality. Specifically, the experiential structure of the utterance (ACTOR + PROCESS: ACTION + CIRCUMSTANCE: TIME) along with the modal operator 'can' specifies a value that serves as the desired interaction outcome in the situation. It individuates a future interactive potential in the situation. The experiential structure of the utterance sets up a form of extended, virtual action-perception that is specified by the semantic differentiators that comprise the utterance. This virtual structure modifies the content of the prior uncertainty gradient and its matter-energy flows. In so doing, it constrains the action-perception possibilities of the addressee by specifying an action format, an action oriented to the addresser's perspective ('come in'), an action role ('You' as designated performer of the action), and a time ('now'). The perceived language structure is one of a potential set of actions that seek to influence the current critical state of the addressee in the situation with reference to a concrete space of possibilities (Section 9). The virtual, as Deleuze (2004 [1968]: 263) explains, is a fully real component of the hypothetical situation in which our example might occur. The virtual, Deleuze (op. cit.) further explains, is not opposed to the real, but to the actual. This is so in two ways.

First, the utterance qua vocal tract action is a physical-material process at the same time that its real-time dynamics are constrained by virtual patterns emanating from longer, slower cultural dynamics. These dynamics give rise to the perception 'in' the utterance of wordings (lexicogrammatical patterns) as extensive crystallized formal structures. These structures are the stuff that linguistics has reified as 'language' whilst at the same time ignoring or failing to see the intensive ecological flows of matter, energy and information that are catalyzed along gradients of uncertainty and which make these crystallized formal structures possible. Secondly, these virtual-yet-real patterns set up and constrain, as noted above, potential interaction outcomes that can be actualized in the further development of the situation as different classes of multimodal events, e.g. the addressee 'comes in', that are semantically differentiated by wordings. Multimodal events are the catalyzed outcomes of linguistic catalysis. They do not necessarily correspond to action performances though they always entail changes in the physiological arousal and neural activation of the human bodies that are affected by languaging behaviour. Seen in this light, multimodal events can correspond to flows of action, perception, cognition, and feeling, seen as the actualizations of the forms of virtual experience that language has the capacity to evoke. Lexicogrammatical patterns in 
language can constrain an attunement to virtual forms of experience along with an orientation to the cultural rewards that derive from aligning to these patterns. These virtual linguistic patterns are very different from the patterns specified by the immediate physical environment (Verbrugge 1980: 93-94; Thibault 2011: 220-223). Virtual linguistic patterns are like Deleuze's concept of the Idea (see also Section 23):

A multiple ideal connection, a differential relation, must be actualized in diverse spatiotemporal relationships at the same time as its elements are actually incarnated in a variety of terms and forms. The idea is thus defined as a structure. A structure or an idea is a 'complex theme', an internal multiplicity -in other words, a system of multiple, non-localiseable connections between differential elements which is incarnated in real relations and actual terms.

(Deleuze 2004 [1968]: 231; italics in original)

Moreover, the differential elements and their relations are not defined negatively in terms of oppositions as in the structuralist tradition of linguistics that harks back to de Saussure. These elements are, in the words of Deleuze, constitutive of a "pure positivity, in the form of a problem to which are assigned relations and points, places and functions, positions and differential thresholds which exclude all negative determination and find their source in the genetic or productive elements of affirmation" (Deleuze 2004 [1968]: 258). These genetic or productive aspects of differentiation have the functional capacity to individuate actualized solutions to the virtual problem spaces that are created in language. The virtual linguistic pattern induces a focus on the relevant or salient properties of the environment that the speaker wishes to harness at the same time that irrelevant ones are filtered out or damped down so that the desired causal chain of elements and events can be actualized and productively channelled as an assemblage. The differential elements and their relations in the linguistic utterance assign a value-weighted distribution of the important and the unimportant in the defining of the problem space, e.g., the relevant degrees of freedom, what is salient, what does not matter, who does what, when, etc. The singularities and affective capacities of the addressee's body are meshed with those of the relevant spatial environment affording locomotion and a stable spatial orientation, the location of the addresser, the virtual pattern of differentiations in the utterance, etc. in order for an embodied multimodal event to be actualized as the solution to the virtual problem space constituted by the linguistic utterance.

The utterance, by virtue of being said in the given situation, exercises a capacity to affect the intended addressee just as that person has the capacity to be affected, i.e. the utterance can bring about material bodily changes in that person's body by prompting a change in the internal organization of the person when his or her body is taken by the catalytical action of the utterance to one of that person's thresholds of self-organization. Capacities are virtual until they are actualised. A person can be taken to a particular threshold of self-organization when a set of patterns and thresholds is installed through habit and routine in that person or a population of persons by means of the catalytic capacities of utterances. The utterance is an order parameter in the sense that its grammatical structure specifies through a process of semantic differentiation a particular locus of cognitive or perceptual processing. The utterance 
is a control parameter in the sense that an intentional semantic content flows from the source (the speaker) throughout the entire action trajectory so as to shape and modulate it until the trajectory reaches its conclusion (Section 16). The end result is a modification in the internal organization of the addressee, whose potential for action is transformed. It is sustained, habitual engagement with utterances and the physical and other events with which they covary that sets up through apperception the patterns and thresholds of physiological arousal and neural activation that utterances have the capacity to amplify or inhibit through their catalytical action.

In languaging behaviour, these parameters and their variations can trigger a switch in the distribution of attractors that define the state space of the situation. In this way, a given distribution of attractors is transformed into a different, topologically non-equivalent one that gives rise to transition points between phases. A situation or situation-type is a region of stability and transitions between regions defining a structured space of possibilities. A situation is, to use Deleuze's term, a virtual multiplicity (Deleuze 2004 [1968]: 230-231). Multiplicities are virtual, but not actualized. They can be actualized in a variety of ways. The tendency of the addressee in our hypothetical example to 'come in' is, in the situation, real at all times even if the person is not actually undergoing a phase transition triggered, say, by the addresser's utterance. Moreover, the phase transitions can be actualized in a variety of ways, not necessarily linguistic. The specific means of actualization of the tendency to 'come in' may vary. Languaging, as noted above (Section 9), is a culturally shaped mode of exploratory activity that changes the content of uncertainty gradients.

The fundamental question is: how to characterize the information that supports the perceiving, understanding, and acting of the individual or group in relation to its macroscopic (ecological) environment - the world in which we live. Information in the specificational sense is not about and does not stand for the things in the world, but is specific to them. Grammar can be seen as a scaling up of the agent-environment system so that the many fluctuations and variables on the micro-scale are subject to more and more constraints on the macro-scale (ecological scale). This means that language is geared to the perceiving and understanding of both the persisting and changing properties of the world. This further means that macroscopic 'grammatical' information is dependent upon and specific to the natural properties of the agent-environment system at the ecological scale.

Rather than viewing information as an abstract commodity to be exchanged, I would pose a different question: what kinds of event structures (spatial, temporal, etc) must be brought into coordination with the structure of language in order to achieve the required perception or understanding? Consider the situation in the official FAA recording of the conversations between the pilots of Lufthansa 405 and Speedbird 226 and ground controllers about the night-time UFO sighting by the pilots that occurred at 03.24 on $18^{\text {th }}$ November, 1995 over Long Island, NY. The entire recording can be listened to on YouTube: http://video.google.com/videoplay?docid=-4398747992022736462 
Consider the following preliminary exchange between the pilot of Lufthansa 405 and Boston Center immediately after Lufthansa has first sighted the anomalous traffic:

Lufthansa 405: Ah Boston, Lufthansa 405

Boston Center: Lufthansa 405 go ahead

Lufthansa 405: Ah ... we just ah ... past traffic ah ... on our left wing ah about two, three thousand feet above us ah ... what kind of traffic was it?

None of the speakers (the Boston ground controller and the pilot in their respective aircraft) are co-present. They have to coordinate their spoken descriptions with their respective understandings of spatial and visual fields and their readings of specific instruments concerning altitude, heading, speed, and so on. The episode takes place at night. In the situation, the properties of the language become important determinants of the kind of socially coordinated and distributed perception and thinking that takes place about the phenomenon - the UFO - observed by the pilots in their respective aircraft (Lufthansa 405 and Speedbird 226) and discussed by the pilots and the ground controllers. Rather than seeing this unique workplace environment as one in which individuals 'use' language to produce and process information about the situation, we can, following Hutchins (1995a, 1995b), put the focus on the socially distributed nature of the thinking that takes place and the way language functions to support and shape this thinking. The language interacts directly with the properties of the event and in ways that affect the properties and capacities of the larger thinking system and its components.

Language plays a crucial orienting role in which all participants (pilots and ground controller in our example) experience virtual semantic structures that the available lexicogrammatical formats assemble and evoke as a form of extended virtual perception. Verbrugge (1980: 83) argues that language affords virtual perception and action. According to Verbrugge, language has the capacity to induce us "to experience events, to view them from fixed and moving points of observation, to move about in social and geographic environments." (Verbrugge 1980: 93). Virtual experience of this kind is distributed over the various participant-observers in the event at that same time that the experience is deictically grounded in the subjectively felt experience of each of the participants relative to their specific locations in this particular dialogical array. Thus, "on our left wing" and "two, three thousand feet above us" depend on sensori-motor knowledge for their deictic grounding in the embodied perspectives of the various observer-participants in the event at the same time that the lexicogrammatical patterns of the Lufthansa pilot's utterance evoke virtual structures of perception that are assimilated to past experience on the basis of apperception. It is in this way that the participants in an event of this kind can reciprocally attune to structure in ways that guide action, perception, cognition, and feeling (Thibault 2011: 220).

\section{The Language Stance}

Cowley (2011) argues that we learn to adopt a 'language stance' on the dynamics of firstorder languaging. In ascribing linguistic behaviour to ourselves, to other persons, to robots, he suggests that we adopt a 'language stance' that serves to predict and account for such 
behaviour in terms of our culturally shaped ideas as to what constitutes 'language'. On this view, we ascribe wordings to patterns we see and hear in the dynamics of first-order languaging behaviour. Does this mean that all languaging behaviour is a matter of ascription? Can we ascribe languaging to a talking ATM machine? Is this on a par with talking to another human? I think not and I am sure that Cowley would agree. My worry is that we risk conflating the clearly derivative languaging of the ATM with the languaging that goes on between persons. According to Cowley, nature's trick is that humans learned to recognize and to respond to second-order cultural patterns such as wordings in the dynamics of first-order languaging behaviour. First-order languaging is naturally expressive and elicits interpretations between persons. Recognizing and interpreting second-order patterns can be an important aspect of this process. Rather than explaining it as the ascribing of a language stance, I think we can also tie it to the developmental emergence of reflexive awareness and the forms of knowledge this makes available. In my view, this helps us to build a clearer explanatory link between wordings as second-order cultural constraints on first-order dynamics and the fact that we perceive these wordings as intentional semantic contents in actual occasions of interaction when we adopt the 'language stance' towards our own and others' utterance activity.

Wordings and the perception of wordings in languaging dynamics are a form of reflexive awareness - awareness of second-order 'linguistic' properties of the dynamics. First-order languaging already constitutes awareness of an ongoing interaction with one's environment on account of the sensorimotor coupling of agent to environment in the formation of an agentenvironment system. First-order languaging is a mode of catalyzing (experiencing) the agent's world. First-order languaging is a first-level interactive system with which agents can explore and differentiate their worlds. Second-order language, on this view, is a second-level interactive system that takes as its environment the dynamical properties of first-order languaging and its interactions with its environment and interacts with that environment. First-order dynamics thus become an object of reflexive awareness that adds its own layer of differentiations to those made by first-order dynamics. The resulting system manifests newly emergent properties not fully reducible to first-order dynamics at the same time that secondorder processes feed-off and cannot exist without the environment of first-order ones.

These include various possibilities: (1) selectively reflecting on aspects of first-order dynamics and their effects; (2) developing meta-linguistic criteria for making explicit aspects of linguistic structure and making these objects of meta-linguistic analysis and reflection; (3) reifying or objectifying aspects of linguistic organization or structure and referentially projecting these out of language onto features of the world as in standard correspondence theories of reference; (3) re-describing aspects of the dynamics as phonological features and then re-categorising these as morphosyntactic or lexicogrammatical features and patterns that have 'semantic' values assigned to them; and (4) making explicit the categories, knowledge claims and presumptions concerning the relations of agents to their worlds that provide a folktheoretical resource for accounting for and keeping track of one's self and others across times and places with respect to a normative fabric of commitments, obligations and responsibilities 
that constrain these same interactions and the folk-theoretical basis of the semantics used to account for and understand them.

Grammar is often assumed by linguistic theories to be a theory or model of the world. Instead, it is a folk-theory that provides normative, culturally shaped semantic resources for making sense of the human world. It makes available an explicit framework for talking about and rationalizing human behaviour in terms of a narrative-like structure of values and dispositions. These can include, for example, what something meant, what a term refers to, the intended meaning of a word, etc., the psychological states and dispositions of interactants, their reasons, intentions, motivations, feelings, attitudes, evaluations, and so on. Linguists, psychologists, and philosophers err when they ascribe to grammar ontological categories in either the world or in mind. The resulting linguistic reflexivity can potentially yield further levels of knowing in a hierarchy of such levels as each new level interacts with the environment of the lower levels and yields new differentiations with respect to the new level. Such differentiations would afford the possibility of knowledge of higher levels of abstraction, e.g. the formulation of the constraints that yield the meanings of sequences of clauses and sentences and their relations and meanings (Harris 1991: 336); or the formulation of the grammar and semantics of a distinct scientific sublanguage that are not necessarily sublanguages of any one natural language (Harris 1991: 290-291).

Third-order (discourse?) level interactions take as their environment not just second-order interactions. Rather, third-order interactions interact with the environment of second-order interactions interacting with first-order ones. This conception is totally different from the standard levels accounts of language, see as consisting of a number of inter-related levels or cycles of coding, e.g., phonology, graphology, lexicogrammar, and discourse. In such accounts, each level is either the means of encoding some other levels or of decoding some other level where each level is either the coded input or output to some other level. On the present account, each level constitutes processes of interactive differentiations with respect to the other levels with which it interacts, i.e. processes that catalyze the experience or meaning for the agent of these multiply constrained organizations of potentialities for agentenvironment interactions.

\section{Grammatical Operators as Catalytical Constraints on Socially Organized Flows of Matter and Energy}

A person's vocal tract activity is an environmental event that has the functional capacity to trigger or catalyse material changes in a body or a social assemblage of bodies. A conversation between persons is a socially organized assemblage of bodies in this sense. In conversation, humans co-orient to each other and to relevant aspects of the worlds in their milieu at the same time that the conversation has a well-defined spatial structure and temporal duration (see Scheflen and Ashcraft 1976; Thibault 2008; DeLanda 2011: 16). Utterances can prompt a change in the internal structure of the individual when that body is pushed to one of its thresholds of self-organization. What we need to look at are not the separate bodies occupying different locations in Cartesian space (Section 32), but the thresholds of intensity 
that can cause cognitive, affective, and other transformations of these bodies, both individually and as socially organized assemblages of bodies.

Deleuze's concept of the intensive refers to physical properties such as temperature or pressure that can form gradients containing potentially productive flows of energy. For example, a temperature gradient results from the coupling of hot and cold masses of air or water. Similarly, pressure gradients result from the coupling of high and low pressure masses. Chemical gradients result from the coupling, for example, of materials with different $\mathrm{Ph}$, e.g., acid and alkaline (DeLanda 2011: 95). Affect gradients result when two bodies with different feeling states and different levels of arousal are coupled. Cognitive gradients are created when two or more bodies with different informational states are created. All of these differences represent differences of intensity that have the capacity to direct flows of matter, energy, and information. Such differences are productive because of the role they play in directing and organizing the flow of matter and energy in the assemblage and the critical thresholds, e.g. of arousal, that need to be activated for the intentional structures of different individuals to be coordinated and/or changed (Freeman 1995: 90-91). Meaning and value emerge interactively as agents orient to and assimilate themselves to the affordances of their environment (Freeman 2000: 89). The choice of one action trajectory over some other is then tipped in favour of the most economical or efficient means of dispersing the locally available energy gradient as agents adapt available resources to their immediate circumstances.

Just as ice turns to water and therefore its manner of spatial organization when it reaches a critical threshold that is supplied by an external source of energy that flows into the ice and affects its temperature (DeLanda 2011: 121), utterances can trigger or catalyze the destabilization of the patterns of activity in the entire sensory cortex, giving rise to a new spatial pattern of activity, which is nonlinear and chaotic (Freeman 1995: 66-67; Sections 1415). This works by installing in a population of interacting individuals a set of persistent patterns and thresholds that are catalyzed by utterances on the basis of routine or habit. Habitual, repeated patterns of interaction between agents make some patterns more standardized and repetitive such that they become crystallized as social routines and culturally constrained or 'grammaticalized' procedures for making semantic structures routine. Grammaticalization is therefore a culturally constrained scaffolding of semantic structure that provides normative criteria for the interpretation of utterances. The question arises: how do patterns and thresholds of physiological arousal and neural activation based on new triggering relations with utterances get installed in an assemblage of bodies in a given population?

The crucial point here is that language is a form of value-realizing behaviour that coordinates the interactions between persons, seen as an individuating process. As Maturana and Varela (1987: 218) point out, the small-scale interpersonal transactions that bonded early hominids in small groups of community and reciprocity based on food sharing, stable sexual relations, cooperation, child rearing, and close emotional bonds opens up an enlarged possibility space of individuating transactions as social individuals explore their relations and their capacities to affect and be affected by each other. The more intensive emotional bonds and solidarity gradients that bind individuals in close-knit communities also afford enhanced possibilities 
for exploring each other as individuals. Bipedalism and the enhanced possibilities this affords for distributing and sharing food among the members of the group, frontal coitus, face-to-face child-rearing, and the sharing of parenting roles between males and females all select for "a biology of cooperation and linguistic coordination of actions." (Maturana and Varela 1987: 222; Freeman 1995: chap. 6; Thibault 2004b; Savage-Rumbaugh 2011).

Interpersonal relations and interactions that afford the intensive reciprocal exploration by agents of the very many fine-grained sensorimotor discriminations and their expressive potential in vocal tract, facial, and gestural modes of co-articulation lead to the emergence of languaging agents with the capacity to narrate their selves and to keep track of the other selves with whom one is bonded in relations of reciprocity and community across place and time scales. Languaging is the individuation of positive, productive differentiations that have the functional capacity both (1) to operate on and transform social reality and (2) to individuate the persons who engage in these transactions as selves that function as valued distinctions in a domain of socially coordinated linguistic interactions. Such interactions afford the recursive exploration and narration of selves through the making of finer and finer expressive distinctions whereby selves and their stories are operated on and transformed when expressive distinctions become an object of reflection in coordinated languaging behaviour between agents. Languaging does not directly reveal or express the inner states of individuals. Insofar as it both stabilizes and intermediates between the pico-scale dynamical properties of individuals and the larger-scale social and cultural dynamics of populations of individuals (Section 24), languaging affords semantic differentiators that are decoupled from online perception-action. Decoupling means that semantic-pragmatic strategies of concealment of motive and intention can be entertained and enacted so as to further the interests of individuals in their dealings with one another. Recursively self-maintenant languaging agents have learned to exploit and adapt social and cultural norms for the invention and narration of selves that serve the strategic purpose of enacting and negotiating modalised intentional stances with others (Ross 2007). The 'language stance' (Cowley 2011; Section 27) thus serves the self-maintenance of the agent (Section 8) by enabling the agent to manipulate the reflexivities of situations and their conventions along with the interactive potential of these situations for its own strategic purposes.

Persistent patterns of vocal tract gestures, not individual behavioural units, change the individual's relationship to its environment. The selection pressure is on combinations of units in co-articulated vocal tract behaviour and populations of resources. The 'grammaticalization' of these unit-combinations is then a population-level adaptive response by way of standardization of and reduction in complexity of sensori-motor procedures that enables languaging agents to adapt to and reflect on language (Argyropoulos 2008; Section 5). Lexicogrammatical patterns are socially distributed and culturally transmitted routines that select for certain kinds of learning, cognition, and organized behaviour in the interactions between the persons who belong to the same interpersonal network. The pico-scale behavioural units of first-order languaging behaviour are measurable on timescales ranging from milliseconds to fractions of seconds (Section 4). That is, units on these time scales have the functional capacity to be salient in some way in the interactions between persons and 
between persons and their environment. Because they have the capacity to be salient, they are capable of making a change in the individual's or the group's relationship to its environment. The physical, social, and cultural affordances of the environment are, typically, far more persisting than are the pico-scale dynamics of first-order languaging behaviour on any given occasion (Reed 1996a: 30).

Persistent patterns of vocal tract behaviour are 'grammaticalized' in the sense that they become routine and norm replicating. Lexicogrammatical patterns are norm replicators in this sense. Such patterns express one's belonging to a group or interpersonal network. They do not cause behavioural responses in others; instead, they act as triggers or catalysts for behavioural responses of conspecifics that are presupposed to possess complex internal organization (DeLanda 2006: 22). This internal complexity, DeLanda points out, is not explainable solely in terms of material causes such as being in possession of a nervous system of a certain kind. Linguistic catalysts imply the existence of reasons for acting, predispositions to act, and beliefs as to the existence of a particular social order or set of implicit underlying representations and associated subjective gradients (DeLanda 2002: 194). The routine nature of lexicogrammatical patterns can lead to explanations that obscure their true functionality.

For example, Langacker (1987) views grammar in terms of cognitive routines that model internal cognitive or mental processes (Section 3). Halliday (2004) views them as the outputs of an abstract systemic potential that is social in origin (Section 1). Both of these views obscure the ways in which lexicogrammatical patterns are catalysts that are not reducible to either of these views. Moreover, both views fail to show how languaging behaviour often involves the successful manipulation of causal chains of events that are not reducible to either abstract mental or cognitive faculties or the formal outputs of choices from systems in the form of 'text'. The routine and norm replicating characteristics of lexicogrammatical patterns have been honed by their application to problem solving situations over many generations (DeLanda 2011: 24). These patterns may appear to be habitual formal patterns while also being able to catalyze successful causal interactions between material entities and to direct flows of matter-energy in the social world.

Lexicogrammatical patterns are cultural replicators. They arise in a given population of interacting agents largely as a statistical consequence of the many efforts of individuals to coordinate their intentional interactions with each other on the basis of stable conventions. On the individual level, utterances are intentional acts at the same time that they are shaped by and conform to norm replicating patterns that are an unintended statistical consequence of the many efforts of individuals to coordinate their actions with each other in mutually comprehensible ways. On the other hand, utterances can catalyse beliefs corresponding to underlying presupposed networks of representations that are the result of socialization through the agencies of family, peer group, school, etc. However, linguistic catalysts act as triggers, not causes, of these representations. In a given population, a given linguistic operator can trigger or catalyze variable representations according to socialization effects that are variable and are accordingly distributed in variable ways throughout a population. 
Linguistic utterances do not replicate in the biological sense - they do not replicate using a self-assembly code as does DNA. Instead, we interpret them on the basis of apperception. In this way, utterances get integrated to networks of representations that are stored in memory on the basis of prior experience. Utterances are grounded in apperception (James 1899; Bickhard 1998; Thibault 2005a, 2005b): they have the capacity to induce an apperception of previously experienced (and remembered) events with which the vocal pattern covaried (Verbrugge 1980: 94; Thibault 2011: 220-223). Linguistic utterances have the functional capacity to trigger or catalyze networks of associations that can, in turn, evoke associations with other events and thereby add to, subtract from, or otherwise modify the network of associations in ways that catalyze flows of cognition, feeling, and behaviour. Networks of associations are constituted by stable patterns of neuronal activity called distributed representations. Their content is a prototype based on a sample of a population of linguistic utterances that are detected by the individual. Their prototypical content is derived from objective statistical properties of a population (of utterances), which an assemblage of neurons can transform into a subjective experience of an apperception. Apperceived experiences are not stored in the physical connections of neurons. The only thing that is stored is a configuration of connection weights or values in a particular neuronal assemblage. A given utterance (or other stimulus) can set off the original, stable pattern of activation. The neuronal network stores a set of properties in the form of value-weighted connection strengths that give the neuronal network the capacity to activate the prototype as a subjectively experienced conceptual-semantic structure when the right stimulus occurs. Subjectively experienced and felt conceptualsemantic networks that are activated in this way can affect the individual's behaviour.

I shall now look at a brief transcription taken from a video recording of a conversation between Paul, the husband, and Dion, Paul's husband concerning the mess that Paul's pet cockatoo, a species of parrot indigenous to Australia, has scattered from his cage onto the kitchen floor. Paul has just returned home from work. The conversation takes place in the presence of Barney, the caged cockatoo, in the kitchen. The transcript of the verbal data is as follows:

Dion: (1) yeah (as if answering for Barney) (2) what's he spilt it already? (3) look at the mess, Paul (4) you're gonna have to clean up in here (5) it's a pigsty

Paul: (6) it is rather a pigsty

Dion: (7) yes (8) well (9) it's your animal

Paul: (to Barney): (10) you make a mess Barney (11) you make more mess than I do everyday

The following analysis is of clauses 3-5 only. Dion grounds her intentional orientation to the situation in an appeal to community norms concerning matters such as who is responsible the cleaning up of the mess caused by the pet cockatoo as well as norms of tidiness and cleanliness. In doing so, her utterance is empowered with the capacity to affect the addressee, her husband, Paul, on the basis of such community-held norms that bind its members to each 
other in relations of obligation and responsibility. It is on this basis that persons have the capacity to affect others and to be affected by them through their languaging activity. In the verbal transcript and the video recording on which it is based, Dion seeks to secure a commitment from her husband that he will take responsibility for cleaning up the cockatoo's mess. Cockatoos are excellent talkers and yet it is interesting to know that Dion does not seek to hold Barney (the cockatoo) responsible, but her husband. The reason for this lies in the fact that Barney is not presupposed to possess the necessary criteria of personhood: he does not the capacity to be affected by the utterance in the way intended by Dion. Barney is but a peripheral player in this language game. In other words, Paul, but not Barney, is endowed with the normative status of a social person who has the capacity to be affected by his wife's utterance in the intended way. Utterances have the functional capacity to transform the social status of persons by, for example, holding them responsible for their actions or conferring specific expectations, commitments and obligations on them. Dion's utterance serves this function (Section 8). Such capacities are exercised in and through the utterance-activity of persons. In this way, utterances have the functional capacity to transform the socio-cognitive status of someone. When this occurs, we can say that these capacities have been actualized.

Dion's utterance assigns a value-weighted distribution of the important and the unimportant in the defining of the problem space (Section 26). The utterance specifies, from her point of view, as analytically re-constructed by me from my own observational perspective, the relevant degrees of freedom of the participants, what is salient, what does not matter, who does what, when, etc. The singularities and affective capacities of the bodies of the participants are meshed with those of the relevant aspects of the situation (e.g. the mess caused by Paul's cockatoo's scattering his seed on the floor) affording perceptual coorientation, with the respective locations and points of view of the participants both with respect to each other and also the relevant aspects of the scene, with the virtual pattern of differentiations in the utterance, the proposed course of action, Dion's proximate intention, Paul's willingness to commit himself, the relevant community norms that are appealed to, etc. in order for an embodied multimodal event to be actualized as the solution to the virtual problem space constituted by the social-affective-cognitive assemblage which Dion's utterance helps to create.

Clause 1 is imperative mood of the subcategory [JUSSIVE: SUBJECT IMPLICIT]. More specifically, it serves the function (Section 8) of directing Paul's attention to the mess in the kitchen, as specified by the choice of Predicator look at and the Complement the mess, along with the vocative element Paul. The three clauses comprising Dion's utterance are analyzed as follows, drawing upon and adapting some principles in Hasan 2009 [1992]):

- Express Proximate Intention: Make a claim on Paul's attention and make him aware of the mess ('look' in clause 3); get him to clean it up ('you're gonna have to clean up in here') (clause 4);

- Give a Reason-Explanation: it's a pigsty (clause 5); 
- Ground the utterance consisting of the three clauses in relation to a more general principle: 'clean and tidy kitchens are healthy, desirable, etc.; messes caused by pets are not';

\section{- Appeal to a Community-held Validity Claim as the ultimate grounds of the}

utterance: Norm Conforming Attitude towards Community Norms of 'tidiness' and who is responsible for cleaning up messes.

Clause 4 selects declarative mood combined with a number of other lexicogrammatical selections. These features include the putting of the second person pronoun you in first position, the future orientation in going to, the modal operator of obligation have to, the lexical specification of the desired course of action clean up, as well as the locative circumstance in here. Significantly, clause 5 follows these two clauses. Its function may be glossed as [GIVE A REASON FOR/MOTIVATE THE DESIRED COURSE OF ACTION], i.e. the proposed action specified in clauses 3 and 4. It also functions to position both interlocutors in a particular attitudinal relationship to the referent situation. The three clauses in Dion's overall speech act function in their various ways to construct and negotiate both an interpersonal relation with Paul by attempting to engage him in a particular way as well as to create a specific, shared attitudinal orientation to the situation.

With specific reference to clause 3, it's a pigsty, I shall now say a few words about the experiential structure of the clause as a semantic operator on the implicit presupposed representations in the situation (again, as re-constructed by me from my observational perspective). Clause 5 can be analyzed as follows:

i. Differentiate the current locus of attention by selecting a variable in the local network topology: the pronoun 'it' exophorically refers to the generalized external situation or milieu in which the utterance occurs;

ii. In so picking out and focusing on the external surroundings (the mess caused by Paul's cockatoo), the pronoun 'it' is conventionally understood to be contextually sensitive to the local requirement that the pronoun is correctly associated with its referent and that the referent is retrievable from the context of utterance (i.e. its reference is locally resolvable or interpretable);

iii. The pronoun 'it' is selected as the local point of departure - the Theme (Halliday 2004: chap. 3 ) - for the development in the remainder of the clause (the Rheme) of a goal-directed actionstructure;

iv. The transitivity (operator-argument) structure of the clause enables cognitive operations on the topology that partition and filter it to a smaller subset of possibilities to which attention is directed according to the specific contrast set that acts as a basis on attraction for the actiontrajectory;

v. The action structure is a time-locked intentional trajectory that is semantically modulated by the speaker's intention all along its trajectory until its conclusion;

vi. The utterance induces apperceptions of representations of pigsties and related matters (see below) by setting up in its transitivity structure a relationship of attribution ('is') between 'it' and the nominal group a pigsty. 
Dion's utterance in clause 5 is perceptually grounded in a situated context on which the utterance operates and which it transforms. Her utterance picks out the external situation that 'it' refers to as the point of departure for a message about that situation and predicates something of it. The verb Process 'is' functions to profile a temporal relation (Langacker 1987: 214-215) between two nodes in the local topology, viz. the situation referred to by 'it' and the nominal group a pigsty. The selection of the simple present tense establishes the speaker, Dion, as the agent who is responsible for the orienting role of the utterance. This stands in contrast to the co-orienting function of the progressive tenses (past and present), which invites both addresser and addressee to attend to the process together. Processes profile temporal relations or interconnections between things at the same time that relations are conceptually dependent on the things that are interconnected (Langacker 1987: 215). In the present example, the Process profiles a temporal relationship between two nodes in the local representational topology, i.e. the mess in the room caused by the cockatoo and evoked or apperceived virtual representations of pigsties, other messy rooms, messy pets, careless pet owners, etc. to which the state of the room is unflatteringly compared and which draw upon a stock of such representations as grounded in prior experience.

Representations are defined by their presuppositions - what is implicit and not explained and by their contrast spaces. (They define what the relevant options for the representation are). The presuppositions are the underlying representational topologies that make up the dimensions of a representational state space, while the state space is defined by a distribution of particular differentiations in that state space, a particular partition of possibilities into distinct basins of attraction. Linguistic utterances are norm-governed actions. This is so in the sense that the members of a common culture regularly associate a particular norm of socially appropriate behaviour with a given class of action. This means that social actors expect each other to make (approximately) the same association and to behave appropriately in relation to the norm that is specified. Experiential meaning can therefore be understood as normative differentiators that have the functional capacity in some social situation that is commonly understood by participants to be associated with or to induce apperceptions of underlying presupposed representations on the part of the various participants in the situation.

Experiential differentiators do not encode representations of mental or social contents. Instead, they are normative patterns that have the power to evoke or to induce situationally appropriate representations that are common to all the participants in the situation.

Categories of experiential grammar (Halliday 2004 [1985]: chap. 5) are differentiators: they do not encode some pre-existing content or state of affairs. Instead, they differentiate (partition) the world (1) by inducing apperceptions of previous experienced situations and events with which the linguistic differentiator covaried in the agent's first-person experience; and (2) in doing so they indicate a usually quite delimited contrast space of possibilities in the form of relevant equivalence classes (Garfinkel 1981: 51-66) of presupposed underlying representations. Statistical learning is relevant here too. Infants learn to sensitize to the distributional patterns of vocalizations, gaze vectors, pointing, and the specific event types with which these covary in the situations in which they are embedded (Section 3). It is in this way that infants learn how language structure attunes them to virtual experience. It is in this 
sense that utterances can be said to operate on a semantically structured space of implicit underlying representations which they transform by adding to them, modifying them, subtracting from them, and so on (see Bickhard 1998: 206). Apperception means that utterances are integrated with previous experience in memory in ways that get channelled in particular directions by the contrast sets of representations that the utterance evokes for participants. Because lexicogrammatical patterns are conventional resources, they have the functional capacity to evoke underlying or implicit presupposed networks of representations that are mutually accessible to all participants in the situation. Thus, utterances are conventional means of specifying implicit systems of representations to all participants on the basis of cultural learning. Participants learn how specific utterance-types indicate more information that is available in the form of the utterance itself by learning the normative conditions under which utterances are conventionally interpreted.

In this way, complex associative networks of representations get built up in memory. The associative connections that are built up through experience form integrated cognitive maps of the person's world as more and more associations are created through processes of adding to, subtracting from, and modifying the underlying representational topology along with its subjective feeling gradients. Habitual or routine experience of vocal and other stimulus events serves to trigger or catalyse apperceptions of similar experiences of such events and the environmental experiences with which they covaried in prior experience. Apperceptions set up cascades or flows of associations that increase in duration and density at the same time that they catalyse further connections as well as complex hierarchies of increasingly abstract terms in conceptual-semantic networks. A vocalization sets off a soliton-like wave in the excitable medium of the brain. The wave forges and accelerates a phase transition when a critical threshold is crossed. In this way, a catalytic pathway to each item in the network is created thereby setting off a self-replicating, auto-catalytically closed network. Every item in the entire network is accessible and retrievable through a catalytic pathway of associations that serve to evoke each other (Carpenter and Davia 2006: 1082; Sections 13-14).

In overcoming the structural constraints of the excitable medium in this way, each item in the associative network is accessible through a catalytic pathway that links all the items in an auto-catalytically closed, semantically coherent network of relations. A network of this kind both gives rise to flows of cognition and is triggered by them in a self-replicating and selfexpanding network of associations that constitutes a thermodynamically more stable structure - a globally coherent assemblage -- than do any of the separate items taken singly. The overall associative network is therefore a thermodynamically more stable product than the individual component items. The catalytic process overcomes the structural constraints of the diverse items' properties and connection strengths and in so doing it facilitates the forging of a catalytic pathway that links all of the items in an overall conceptual-semantic assemblage. The soliton-like wave generated by vocal tract activity delivers the energy that is needed to change the structure of the excitable medium of the brain in order to facilitate the phase transitions required for the network to be activated (Carpenter and Davia 2006: 1082). 
Gabora (2004) argues persuasively that the entire conceptual-semantic network, or "worldview" in her terms, is a cultural replicator, not the individual ideas that comprise it. Her argument is that "a gesture or idea is how a worldview reveals itself in a particular context" (Gabora 2004). This would be so because only a fragment of a person's worldview gets expressed or revealed at any given time. This would mean that the conceptual-semantic network is a cultural replicator, not the individual items that comprise it. However, phonetic gestures (the stimulus) do not express or reveal ideas. This suggests a vestige of the code view that I have rejected. Utterances, as argued above, trigger the activation of patterns of neuronal activation that have the capacity to evoke conceptual-semantic networks. Utterances are culturally stabilized differentiators that serve as indicators of future interactive potential that may or may not be successfully activated (Section 8). Successful worldviews get repeatedly activated and elaborated because they work. Therefore, they get selected and replicated through processes of cultural transmission on account of their potential future success. However, as pointed out above (this Section), phonetic gestures are cultural replicators; they replicate through processes of cultural learning and transmission and enforced social obligation in the sense that languages constitute norms of behaviour to which individual speakers of the language are expected to conform (DeLanda 2011: 56). As external resources that can trigger or catalyze the activation of conceptual-semantic networks in individuals, vocal tract gestures therefore rely upon regular, habitual, norm replicating patterns so that the required population-level entrainment effects can occur (Sections 6, 17).

Linguistic replicators are catalysts that have the functional capacity to amplify or to inhibit the self-organizing processes made possible by intense matter-energy flows. It is these flows that characterize the range of stable states and forms of organization available to a particular social system, not abstract forms variably located in the heads of individuals or seen as the outputs of systemic choices. Lexicogrammatical forms are catalysts in the sense that they are operators that can act as control switches or knobs, so to speak, to select one stable state over another. Lexicogrammatical differentiators are semantic control parameters that specify, informationally speaking, the ways in which a socially organized flow of matter and energy can be affected. They can trigger a qualitative shift from one stable state to another in a system close to one of its critical states (Hollis et al 2009: 217); Section 9). The digitalization of these semantic parameters keeps them constant and discrete. However, other parameters can be varied quantitatively, e.g. semantic grading of, say, adjectives (very good) or prosodic amplification and intensification that increase the amount of energy flowing into the system (a person's body or assemblage of bodies) until a critical threshold is reached, resulting in a cognitive, affective, or behavioural change. Such changes are qualitative, not quantitative. A body or a social assemblage of bodies (human and nonhuman) is qualitatively transformed from one cognitive, affective, behavioural or juridical, etc. state to some other. Moreover, linguistic catalysts, like catalysts in general, mean that "low expenditure of energy can bring about high energy transformations.” (DeLanda 2002: 147). Lexicogrammatical patterns are cultural replicators that can bring about phenotypic effects, for example, when large flows of energy are triggered by a single directive emanating, for example, from the CEO of a large company. 
Such was the case when, on Saturday, $29^{\text {th }}$ October 2011, Alan Joyce, CEO of the Australian airline QANTAS ordered with immediate effect a worldwide grounding of the entire QANTAS fleet and the lockout of QANTAS employees in response to a series of strikes and failed negotiations between the QANTAS Board of Directors and unions representing three different groups of QANTAS employees. (http://www.smh.com.au/travel/travel-news/livefwa-orders-qantas-dispute-terminated-20111030-1mq0o.html\#comments). An airline like QANTAS is a form of social organization that exists in a constant state of metastable readiness. This is only possible because of the enormous expenditure of energy required to hold a certain form of social organization in place in such a state. In other words, the CEO's directive is transformed in a myriad of ways on many different temporal and spatial scales of organizational and individual agency into a large number of smaller flows affecting more specific assemblages that are the parts that make up the whole of QANTAS. As Foucault and DeLanda have shown, this requires the constant drill and discipline of bodies. It therefore requires the control and organization of human and other nonhuman bodies (e.g. aircraft) in social arrangements that enable the flows of matter and energy that define the given metastable states that are characteristic of a particular form of social organization such as an international airline like QANTAS (DeLanda 2002: 147). An act of linguistic catalysis is not necessarily a single flow on a single spatial or temporal scale, but can involve a multiplicity of flows on many different spatial and temporal scales. These can range from an intimate encounter between two persons to the interactions between transnational corporations, nation states, and so on.

Lexicogrammatical differentiators operate on socially organized matter and energy flows in ways that may or may not be successful. A successful differentiation is able to inhibit and/or amplify these socially organized matter-energy flows. A linguistic differentiator acts as a catalyst in the sense that it functions as an abstract operator on, in the first instance, prelinguistic social reality; it can switch these matter-energy flows and arrangements from one stable state to another, i.e. from one attractor to another without itself changing. Second-order grammatical patterns arise in the first instance from first-order languaging dynamics as the mainly unplanned statistical consequences in a population of the constant efforts to coordinate and stabilize intentions, thinking, decision making, and so on around social norms. However, these second-order patterns act back on and constrain the first-order dynamics in various ways. In other words, second-order patterns function as order parameters that set limits on and stabilize the formal shape of first-order patterns. Once this occurs, catalytic constraints start to combine with each other to form operator-argument type dependency and other relations. These grammatical constraints have the capacity to operate on a semantically differentiated world of stable, socially organized matter-energy states and flows, forcing a metastable dynamical system of this kind from one stable attractor to another (DeLanda 2002: 291).

The increasing standardization of these efforts through processes of norm replication and grammaticalization may be seen as a way of making more explicit these intentions, thoughts, decisions, and so on, by allowing for their second-order articulation as grammatico-semantic categories. However, we should not overlook the ways in which these same processes of standardization entail a whole disciplinary apparatus comprising enforcement and 
legitimation practices that are deployed and propagated throughout a population to achieve large-scale forms of coercive coordination required by governmental and bureaucratic institutions and corporations and their agencies for the economic, political, and cultural organization of whole societies.

\section{Affective Capacities and Intensive Processes of Differentiation}

Body movements relate persons to each other. Bodies have active capacities to affect and passive capacities to be affected by the actions of others. During an interactive encounter between persons, body parts undergo controlled transformations in the form of articulated movement patterns that have the capacity to affect others. At any given time, a body comprises capacities to act and to be acted upon to varying degrees or intensities. An interactive assemblage of persons on an occasion of talk acts on these capacities and transforms them in ways that yield emergent effects by virtue of their forming an assemblage with other bodies. Interactional synchrony (Condon and Sander 1974) resulting from the cross-modal entrainment of the bodily rhythms of two or more persons in dyadic interaction is a most basic, hard-wired capacity in this sense. These emergent effects can either mesh productively with bodies to form other connections in the assemblage as a whole, or fail to mesh productively in ways that diminish the power of the body to mesh productively with the assemblage as a whole. First-order languaging is a fluid or mobile assemblage of bodies along with aspects of their worlds (e.g. features of situations, artefacts, technologies, etc.). The micro-temporal bodily dynamics of first-order languaging behaviour tap into the core predisposition of humans to synchronize their bodily rhythms with each other. The reciprocal effects of this synchronization serve to generate the required arousal once a certain threshold of intensity is reached, leading to a spontaneous transformation or reorganization of the interindividual dynamics that couple persons to each other in a dynamical state of interactional synchrony. Persons can entrain to each other's neural and bodily dynamics once the required threshold of arousal has been crossed and prior symmetries are broken.

On this basis, one person is able to affect another person in ways that orient the second person to the first person's locus of cognitive or perceptual processing. In this way, a shared perceptual or cognitive focus is achieved. Our local phenomenology biases us to look at the discrete elements that compose the end result. We see and hear etc. the gestures, the utterances and the achievement of shared cognitive or perceptual focus that results. These elements are, in reality, only the end products of intensive processes of differentiation, i.e. the flows and thresholds that are the necessary processes for the emergence of these end products (DeLanda 2011: 130). The meshing of bodies to form an assemblage sets up the conditions for the progressive differentiation of a topological continuum of intensive differences into a more metric, measurable and segmented material reality corresponding to our familiar everyday world and its 'segmentation' into the familiar molar objects, bodies, events, and so on.

The segmentation of utterances into words and other patterns based on the perception of wordings puts the focus on finished products. These products amount to what Deleuze recognized as 'rigid segmentarities' (1994: 222). Wordings are the second-order codifications 
of what were, in the first instance, the unintended statistical consequences of very many efforts of individuals to coordinate with each other in a population or interpersonal network of interacting individuals. Historically, these emergent second-order consequences of first-order interactions became more and more codified by literacy practices. That is, they were reified as a second-order code of normative typifications that became the basis of descriptive typologies. These typologies are based on descriptions and classifications of the static properties of fixed essences that get reified by a phenomenology of abstract forms, e.g. wordings. Various forms of disciplinary procedures enforce conformity to these norms, including the agencies of symbolic control in the media and education systems.

Wordings are formal abstracta that typically form the basis of many text-based transcriptions of interactional events. This means that such events are treated as reified final products that can be segmented into abstract units of variable spatial and temporal extension. Moreover, the dynamical properties of these products and the units that comprise them are defined as low intensity equilibria, i.e. as formal instantiations of higher-order systemic properties that eliminate the intensive gradients that are the drivers of interaction (Deleuze 2004 [1968]: chap. 4). On the other hand, first-order languaging behaviour is comprised of populations of interacting pico-scale events that are defined by intensive differences that are maintained in a far-from-equilibrium condition by a continuous throughput of matter and energy throughout the lifetime of the particular interactive event. It is only in first-order interactivity that gradients are maintained; the flows and fluxes of intensive differences and critical thresholds of material dynamics define the processes of first-order languaging behaviour. The latter is irreducible to second-order products such as text-based transcriptions and the units into which they are segmented on different levels, e.g., turns, discourse moves, sentences, clauses, phrases, words.

On the other hand, first-order languaging behaviour always takes place between individuals both human and non-human - in a population of individuals. The pico-scale dynamical properties of first-order languaging behaviour are akin to Deleuze's "molecular fluxes with thresholds or quanta" (1994: 222) that are far more fluid, dynamic, and less stratified. They are far closer to our biology and to what make us living, feeling, animate beings. As Deleuze observes of these molecular fluxes, "many things happen on this second line - becomings, micro-becomings, which don't even have the same rhythm as "our" history ... " (Deleuze 1994: 222). Moreover, these micro-becomings, perhaps corresponding to micro-perceptions and micro-affects, fine sensorimotor differentiations that elude their homogenization to second-order constructs, can be harnessed in socially coordinated first-order languaging in ways that give rise to new assemblages, new forms of distributed cognitive systems, new forms of interactivity, and new forms of human intelligence.

On this view, the emphasis is less on the fixed properties of these bodies than on their capacities to affect and be affected in a field of intensive differences (Deleuze 2004 [1968]: 292-302; DeLanda 2002: 62). An interactive encounter between persons puts persons and aspects of their worlds into new functional relationships with one another. Individual persons have a variety of means for forming assemblages with others. Linguistics has tended to focus 
on the intrinsic properties of language, usually seen in typological terms. An enormous amount of descriptive detail has been accumulated in this sense. However, we know less about the capacities of individuals to form an assemblage when persons engage in first-order languaging. Capacities are not the same as intrinsic properties. An utterance can be described in terms of its intrinsic properties, e.g. its phonological, lexicogrammatical, and other properties. However, its capacity to afford interaction with another person is not a matter of yet another intrinsic property (DeLanda 2002: 63). Instead, we need to investigate the productive role that utterances can play in the formation of assemblages when humans exploit distributed cognitive systems to make things happen, to solve problems, etc.

Like affordances in Gibson's theory, capacities are relational; they need to be exercised and therefore they may depend on the co-presence and co-orientation of other individuals, both human and non-human. Capacities are capacities to affect and to be affected. In this sense, they are symmetric. Someone's utterance directed my way affords an opportunity to engage with the other person just as I may say something to him or her thereby affecting the other person and engaging his interest or attention. Languaging behaviour is the "glue and grout of social co-ordination" (Steffensen, Thibault, and Cowley 2010: 208) in such encounters because it articulates heterogeneous elements (e.g. persons, artefacts, tools, technologies, etc.) as social-cognitive-affective assemblages without in any way sacrificing the heterogeneity and autonomy of the component parts, which retain their capacity to be detached from any given assemblage and attached to others. When such a system arises, the capacities of the different components interact with each so that the new whole has emergent properties. By the same token, the new whole - the assemblage -- constrains and enables its components, damping or inhibiting some capacities, amplifying and extending others, as well as adding still others.

\section{Mutual Attunement, Meaning, and Entrainment to Population-level Cultural Dynamics}

In co-ordinated first order languaging between persons, individuals attune to and track in space and time pico-scale bodily events of each other that take place on timescales of the order of milliseconds to fractions of seconds. Individuals adjust their sense organs on these very rapid timescales to explore, to track and to modify the sensory input obtained from diverse sources, e.g. vocalizing, gesturing, head movements, eye gaze, facial expressions, bodily orientation, and so on, in a changing multimodal array that is integrated over time and located in space as a multimodal interactive event. Brains attune to and feed off bodily events on very fast timescales (Freeman 2000: 105). This is an active and intentional process of adaptive exploration of these events. It is a commonplace of many linguistic and semiotic theories to say that meanings exist between persons, not 'in' them, although these same theories are not very forthcoming with causal explanations of the mechanisms that make this possible. No shared physical substrate is shown to exist that would make this possible.

Generally speaking, reified generalities like abstract social or cognitive codes are postulated as the means whereby individuals semiotically mediate their relations with their worlds. We have already seen that vocal tract gestures and the stimulus information that they project into 
the environment do not contain and transmit meanings. The subjective experience of meaning can be activated in the brains of individual persons on the basis of their unique experience. Individual persons have the capacity to affect and to be affected by each other. This includes the capacity to induce meanings in other persons. Assemblages of persons draw on biological and cultural resources to co-ordinate their meanings and activities in ways that can lead to newly emergent structures and possibilities for thinking, feeling, and acting in the assemblage. This is how a distributed cognitive-affective system works. Both bodily activities such as vocalizations and other bodily movements and external resources enable persons to be coupled to each other and to aspects of their external environments.

According to both the motor theory of speech perception (Liberman and Mattingly 1985; McNeilage et al 1967) and the gestural theory of co-articulation (Browman and Goldstein 1992, 1995), listeners entrain to the vocal tract gestures of speakers and reconstruct them in their brains. Fowler (1986, 2010) uses Gibson's (1986 [1979]) theory of event perception to show that speech sounds provide information about the vocal tract events that cause the sounds and that speaker's attune to each other's vocal tract gestures. The listener thus reconstructs and attunes to the speaker's gestures. This has clear emotional and affiliative consequences for the kinds of social bonding that occurs when social-affective-cognitive assemblages of individuals are formed (Freeman 1995: 123-134). This includes in my view non-cognitive emotional or affiliative language - what Malinowski called "phatic communion". Phatic communion "serves to establish bonds of personal union between people brought together by the mere need of companionship and does not serve any purpose of communicating ideas." (Malinowski 1936: 314-316). Attunement also facilitates entrainment to the semantic differentiations in the human forebrain. The perception of the speaker's vocal tract gestures provides the stimulation that can recreate previous patterns of activation that are stored as a configuration of connection strengths in a neural network. The stimulus does not contain a message that is decoded by the brain. Freeman (1995: 66) shows that the sensory cortices at the interface between brains and the external world work very differently from the encoding/decoding model.

First, the stimulus is transduced by the receptor layer into a pattern of action potentials and "then into the cerebral cortex, through the thalamus to cortex" (Freeman 1995: 66). At this point, the stable pattern destabilizes the entire sensory cortex so that the previous state, expressed in a spatial pattern of activity, is now expressed in a different spatial pattern, which is nonlinear and chaotic. Nonlinear and chaotic patterns, Freeman explains, create novel patterns (Freeman 1995: 67). Freeman (1995: 66) emphasises that this new pattern is "triggered, not selected, by the stimulus, and it is determined by prior experience with this class of stimulus." (1995: 66). The stimulus - the vocal tract gesture and the auditory stimulus information it causes to be propagated through the medium of the surrounding air - is not the encoding of a pre-existing message that is transmitted to the listener, who in turn decodes it. Rather, the new pattern that is triggered expresses the "nature of the class and the meaning for the subject" (1995: 66). That is, the stimulus places the cortex in one of its basins of attraction. These are grounded in prior experience and work on the basis of apperception (Section 9). 
The sensory data in the form of the auditory stimulus information provide the listener with information about the speaker's vocal tract gestures (Section 15). In entraining to these patterns and in reconstructing the other person's gestures in the speaker's brain, this data triggers the structuring of the neuroactivity that leads to the activation of socially distributed classes of semantic differentiators in a population of languaging agents entrained to the population-level dynamics. The resulting semantic differentiators are a construction of the forebrain, not the decoding of a pre-existing message that was carried by the stimulus from a 'sender' to a 'receiver'. The perception by the listener of the speaker's gesture and its reconstruction in the listener's brain thus affords the recreation of the stable semantic differentiators that have been sampled from a population of similar patterns which the individual has detected on the basis of previous contextualized encounters with these gestures.

\section{First-order Languaging Dynamics: An Analysis}

First-order languaging dynamics and the reciprocities they create promote habits and routines that builds upon and extends the process which Stern (1997, 1998, 2004) called "moving on", leading to the creation of a succession of now-moments (Section 14). Participants in languaging behaviour move along together, they enact and create a series of now-moments that have their origins in the narrative processes generated in core consciousness by the protoself (Section 11). These brief narrative units lasting no more than a few seconds give rise to intersubjective moments of affect-charged "meeting" which "increase the ability of the nervous system to intensify and co-regulate with someone else's activity, and they occur only when the participants' nervous systems have been able to engage in mutual adjustment and self-regulation -- the condition that Stern refers to as moving along." (Hart 2011 [2006]: 27). These now-moments reciprocally bind the neural and bodily dynamics of dialogically coordinated participants in states of intersubjective entanglement (Section 32), resulting in mutual recognition and shared experience. Moments of dialogically coordinated meeting intensify the flow of affect through the entangled dynamics of dialogically coordinated agents and "promotes the nervous system's capacity for self-regulation and attention control" (Hart 2011: 27), for co-orientation, modification of feeling states, extended perception, and so on. Moments of meeting, as defined by Stern and Hart, are, to quote Hart, "a dyadic expansion of the consciousness." (Hart 2011 [2006]: 27). The intersubjective processes of moving on and the resulting now-moments described by Stern and Hart are, in infant development, the precursors of conversational dialogue. Dialogue can thus be seen as successive loci or pulses of intersubjectively coordinated and deictically grounded experience that loop between participating agents in dialogue and their environment(s). Dialogue is a succession of nowmoments experienced in this intersubjective space-time. These now-moments are metricised rhythmic pulses or intervals of intersubjectively coordinated and deictically grounded experience that interactants co-orient to. Seen in this light, second-order lexicogrammatical resources are forms of cultural scaffolding that enable agents to solve problems of coordination as they attempt to mutually explore each other and move along together in dialogue.

In the following paragraphs, I analyze a brief example to show first-order languaging 
dynamics in action. Using techniques based on a combination of both multimodal interaction analysis and Praat software to analyze speech sounds (Thibault 2011: 223-232), I focus in detail on six micro-temporal or pico-scale phases, which are presented in Figures 4 to 9 below. The episode is transcribed from a television documentary concerning the life of a family in Sydney (Australia). The two interactants, Laurie and Noeleen, who are husband and wife, respectively, argue about Laurie's inability to make any of the pens he is trying to write with work. The somewhat energetic exchange takes place around a bar in the kitchen-dining room area of their home. The analyzed material is no more than a brief example from the longer episode in which it occurred.

\section{Pico-phase 1}

This micro-phase consists of two pulses of energy in which N's vocalizations and body movement are synchronized. In this micro-phase she seeks to secure L's attention and to change L's perception of one of the pens that he couldn't get to work in an earlier phase of the interaction (not analyzed). In the first pulse, the utterance 'yeah' is synchronized with $\mathrm{N}$. turning her attention back to her husband from the adjacent pen rack (on her left) from which she has just taken one of the pens that L. couldn't get to work. She shows the pen, which she is holding in her right hand, to L. The pitch of her vocalization 'yeah' is rising-falling-rising, starting on $1961 \mathrm{~Hz}$, reaching a peak of $2687 \mathrm{~Hz}$, falling to $2015 \mathrm{~Hz}$ before finally rising to $2892 \mathrm{~Hz}$. The rising tone anticipates (Section 4) both her own next action at the same time that it anticipates the re-orientation of L. to the pen in her hand. The second pulse synchronizes the action of her briefly writing with the pen on a piece of paper lying in front of her on the bar top at the same time that she says 'look'. The pitch melody of this utterance is in sharp contrast to 'yeah'. This utterance initiates on a similar pitch range to 'yeah', i.e. 2037 $\mathrm{Hz}$, rises to a peak of $3315 \mathrm{~Hz}$, only to fall sharply to around $1246 \mathrm{~Hz}$. The concluding fall signals closure, not anticipation: she shows her husband that the pen really does work.

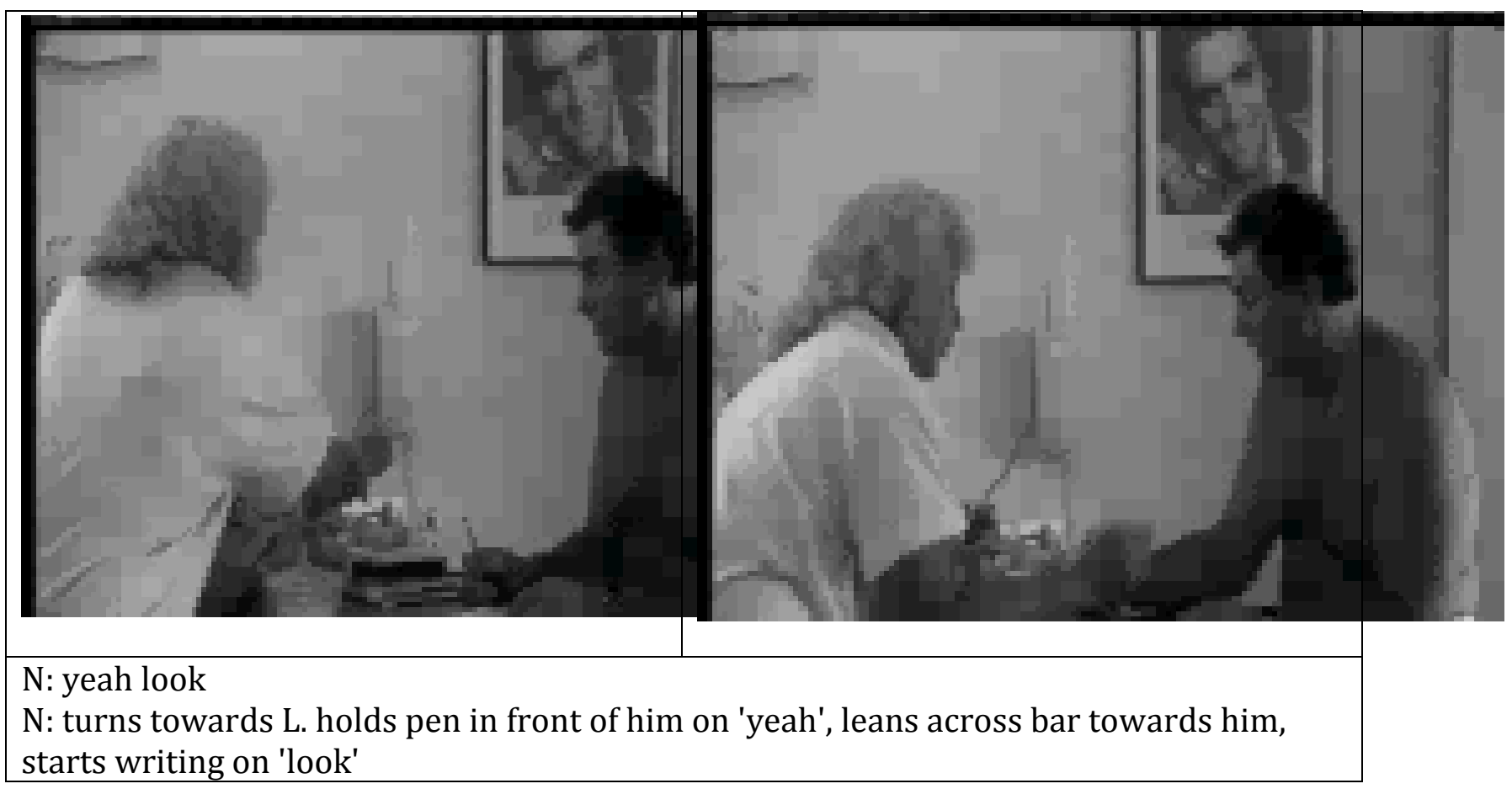




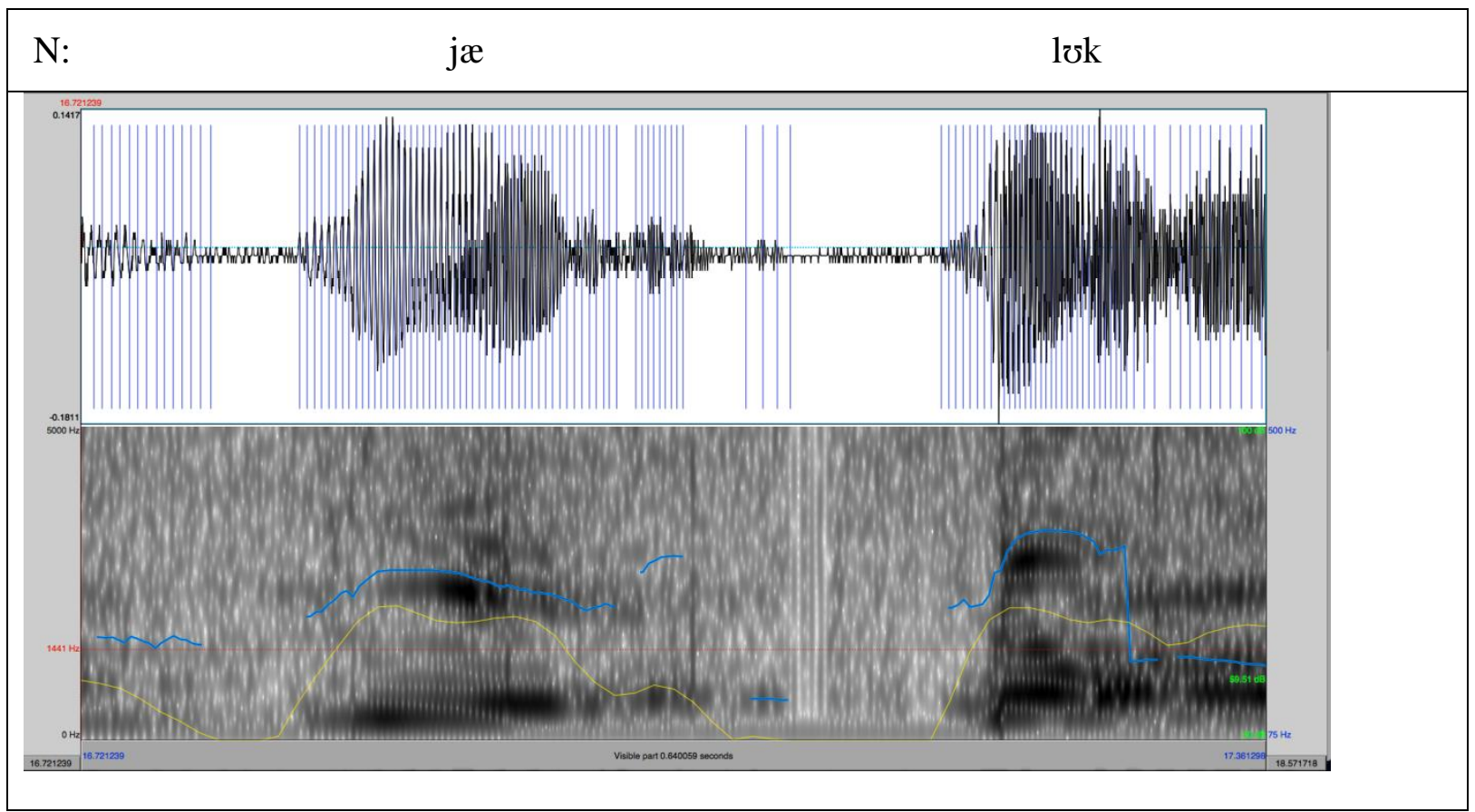

Figure 4: Pico-phase 1

\section{Pico-phase 2}

L's response as shown in Figure 5 consists of the utterance 'one of those I picked up first' during which $\mathrm{N}$. holds the pen in her hand in front of $\mathrm{L}$. The pitch ranges from an initial 1214 $\mathrm{Hz}$ to a final $109.1 \mathrm{~Hz}$. Again, the falling tone signals closure. L is evidently not open to N's demonstration and persists with his own view of the matter.

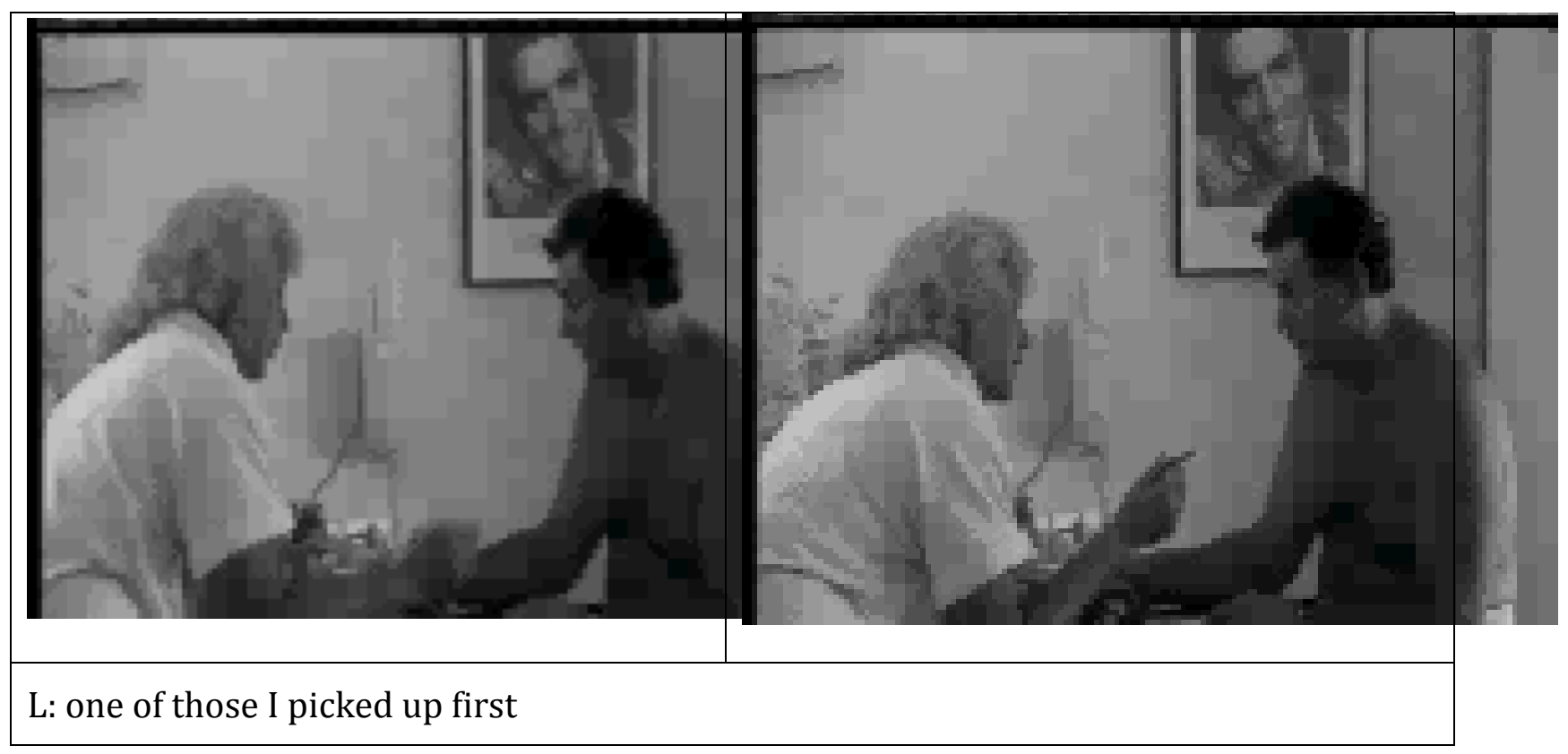




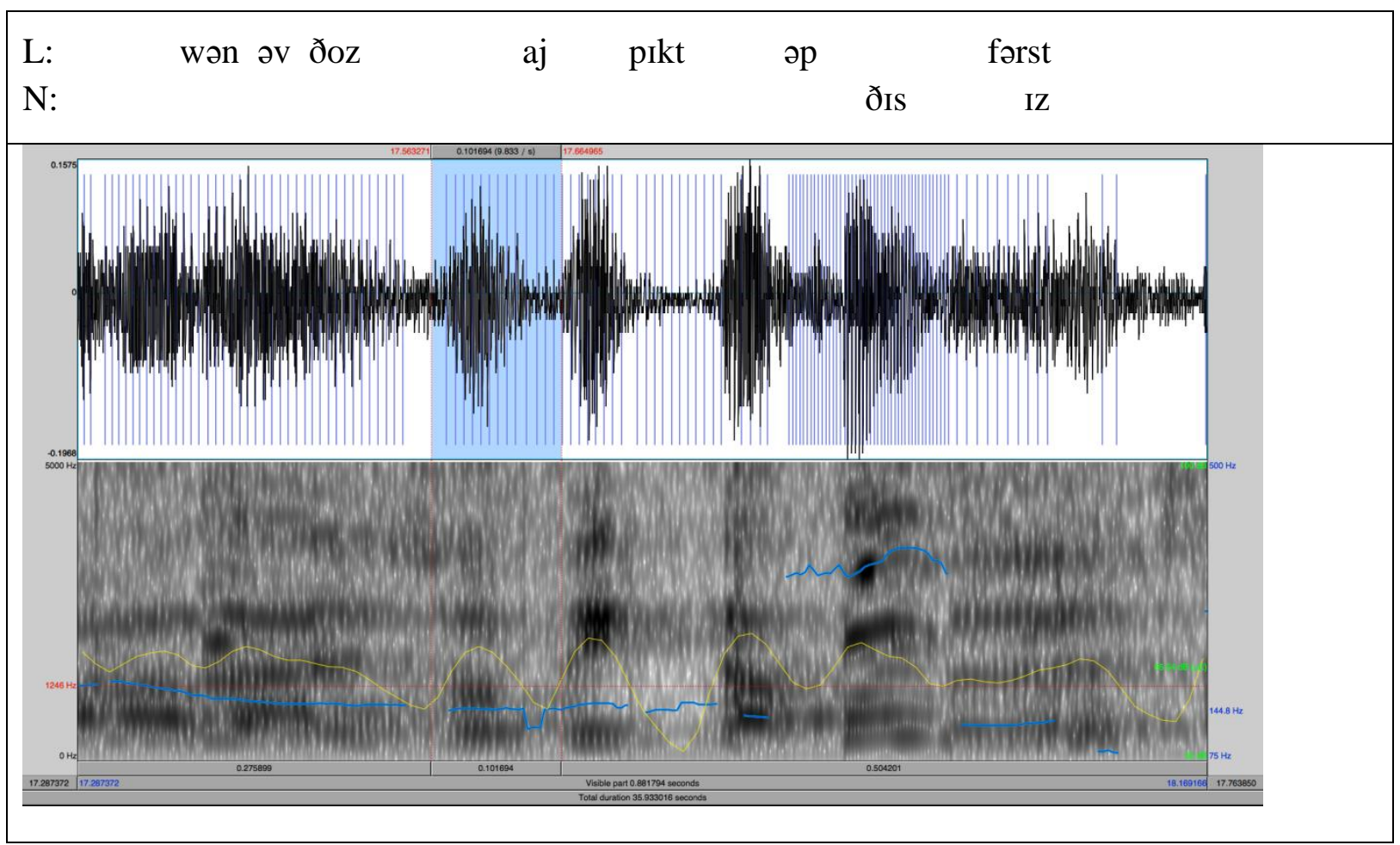

Figure 5: Pico-phase 2

Pico-phase 3

The demonstrative pronoun this in N's utterance grounds the pen she is holding in her right hand to show to L. in deictically felt bodily experience. This can be explained as follows. The English demonstrative this consists of three sub-morphemic markers: /TH/ + /I/ + /S/ (Bottineau 2007: 55). Bottineau (op. cit.) shows that, in demonstrative this, the phonosemantic operator /I/ assimilates past memory (/TH-/) to the item identified in the present (/S/). These three items are sub-morphemic markers or phono-semantic operators that depend on sensori-motor knowledge. The observer's relation to an articulatory event such as $/ \mathrm{TH} /$ is mediated by patterns of sensorimotor dependence, as discussed by Noë (2004) (Section 13).

In the case, of demonstrative this, the sensori-motor knowledge constitutes in experience the representation of the concept /IDENTIFICATION OF INDICATED OBJECT WHICH YOU NOW REMEMBER/. Thus, the speaker, N, invites the listener, L, to locate in the physical world the object, i.e. the pen $\mathrm{N}$ is holding and referring to. Moreover, this object is presumed to have been already referred to, perceived, or otherwise known, in the situation and therefore to be held in concurrent working memory. The nominal group the one you had, which is coupled to the pen $\mathrm{N}$ is holding in her hand to show to $\mathrm{L}$, accordingly assimilates the present act of showing to the past memory of the object. In this way, deictic this anchors the situation in felt bodily experience and in the spatio-temporal frames of reference connected to this. Figure 6, Frame 1 shows how N's utterance, her right arm-hand + held pen, upper body orientation, and gaze constitute a vector of interest and attention that is directed to her 
husband, L. as she shows him the pen and connects this present perception to his immediately prior experience of it.

L's utterance cannot be separated from this whole-body orientation in space and time and concomitant whole-body sensing, but is anchored in it and is inextricably a part of it. In this way, the two speakers establish and sustain a co-orientation frame that lasts for approximately $0.978 \mathrm{~s}$ during which time interval the vocalization is synchronised with the other body movements described above before the shift in orientation indicated in Figure 6, Frame 2 occurs. Figure 6, Frame 2 shows a shift in bodily orientation as $\mathrm{N}$ directs her gaze downwards and begins writing with the pen on a sheet of paper resting on the kitchen bench that lies between the two speakers while L continues writing on his own sheet of paper.

N's utterance this is the one you had partially overlaps with L's prior utterance. Specifically, th- begins slightly before $f i$-: th- begins at $17.863 \mathrm{~s}$ and $f i$ - starts at $17.979 \mathrm{~s}$. The entire unit this is starts at $17.863 \mathrm{~s}$, begins the overlay with first at $17.971 \mathrm{~s}$, with first concluding at $18.165 \mathrm{~s}$, and overlapping and concluding in synchronization with the second syllable of this. These moments of overlap are pico-scale temporal events, having, in the present case, a duration of $0.186 \mathrm{~s}$. The pitch of N's utterance starts on $3055 \mathrm{~Hz}$, peaks at $3531 \mathrm{~Hz}$ and concludes on $293.2 \mathrm{~Hz}$ on had. L's overlapping first is, of course, the conclusion of the utterance analyzed in Figure 5. During the overlap with the start of N's utterance, the pitch range varies very little $-563.9 \mathrm{~Hz}$ to $650.6 \mathrm{~Hz}$. The overlap, the synchronization of the rhythms of the two speakers and the rapid, excited tempo of their speaking demonstrate entrainment effects as they track, explore and modulate each other in micro-time. On initiating this, $\mathrm{N}$ ceases writing (Figure 5) and again holds the pen in front of L, only to resume writing on conclusion of had at the end of her utterance. Throughout the duration of this utterance, N's gaze is directed to L, before then being directed towards the writing task on saying had. L's gaze is similarly directed to $\mathrm{N}$ in the same time interval. Again, this microphase shows how language works synergistically with perception to orient to the environment as a whole-body process in order to adjust to and explore the environment, including environments that are not available to online perception.

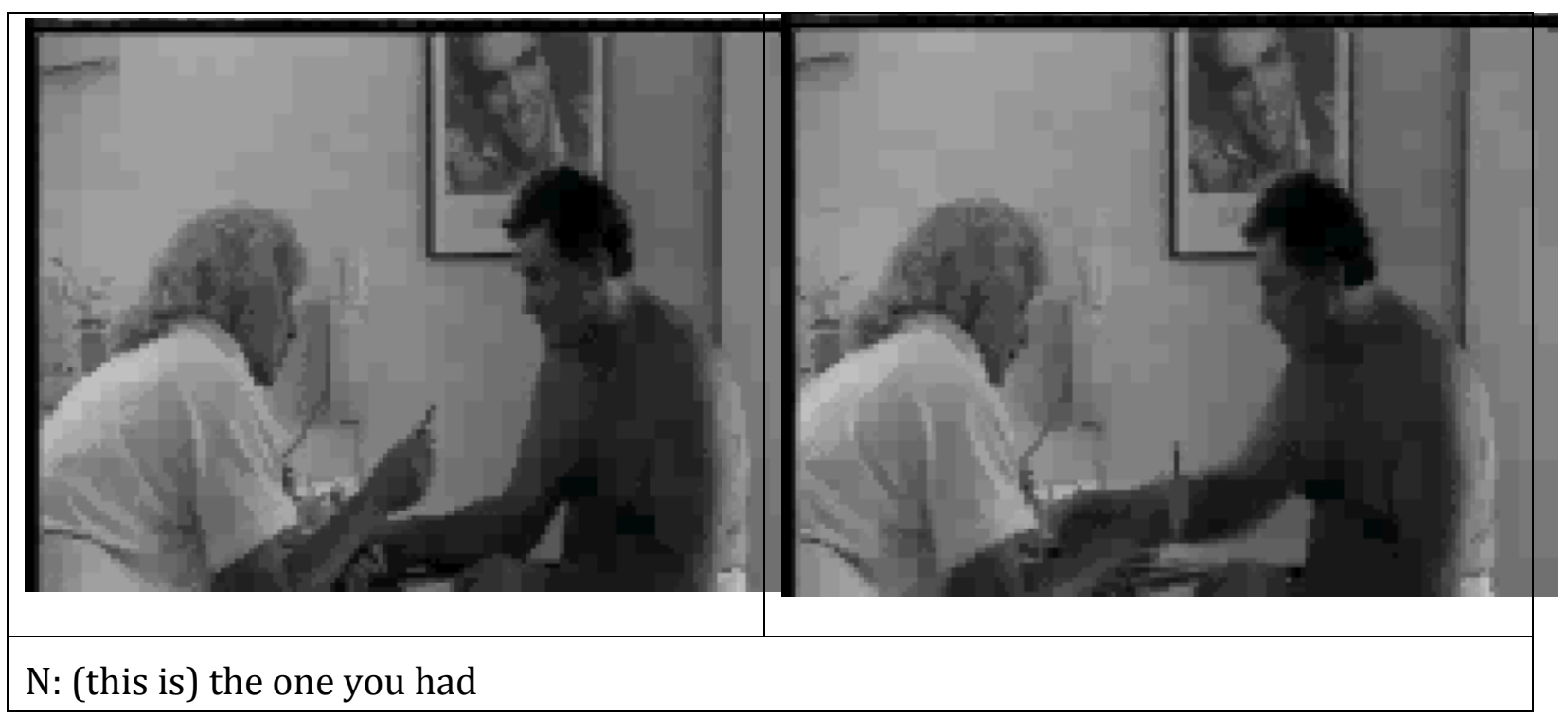




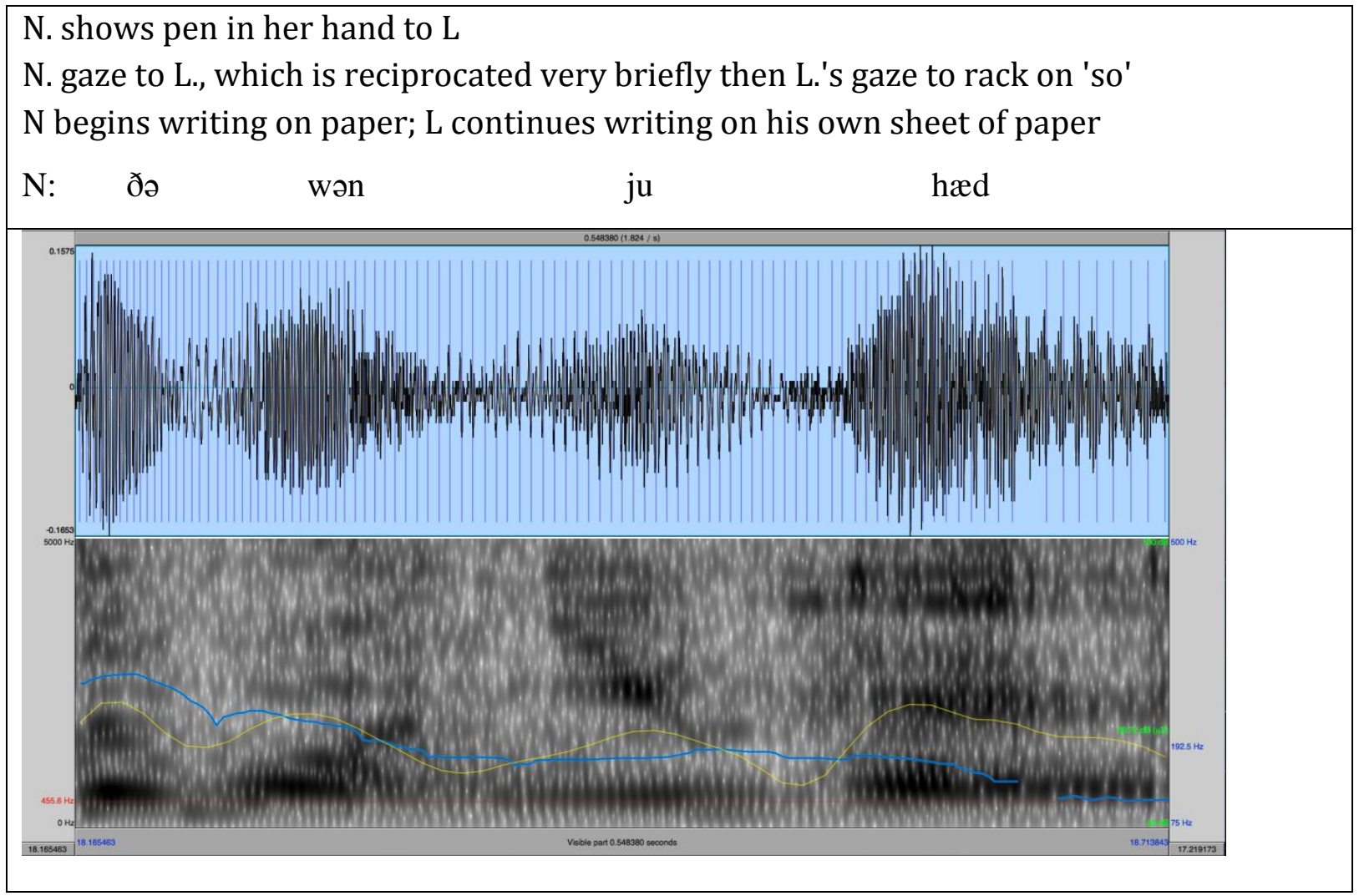

Figure 6: Pico-phase 3

\section{Pico-phase 4}

In this micro-phase, L's utterance so I picked up one of those first synchronizes with the following body movement. In the initial phase of the utterance, L raises his left arm-hand, which is holding a pen in order briefly to show it to N. His hand-arm performs a pronounced downward beat gesture that is co-temporal with first, which also receives a great deal of emphatic stress. During this time interval, $\mathrm{N}$ continues writing on the paper; her gaze is oriented to that task. When L utters first this coincides with N's uttering of right, which is synchronized with her head nod. L's gaze is fixed on N throughout the entire utterance. N's body articulates two principal orientations simultaneously. The primary one is expressed by her overall body position, her body posture, her gaze vector, and the position of her handsarms - all of these elements are co-synchronized and oriented to indicate her orientation to the writing task. Without modifying this orientation, N's uttering of right and her co-temporal head nod as L utters first indicates a second, nested orientation, which is to what her husband is saying.

The pitch range of L's utterance is from an initial $1257 \mathrm{~Hz}$ to a closing pitch of $1420 \mathrm{~Hz}$. The rise, as before, has an anticipatory function. In this case, L signals his intention to continue to hold the floor as he continues to develop his utterance (Figures 8 and 9). The brief overlap of L's first with N's right lasts approximately $0.170 \mathrm{~ms}$ and is characterized by a noticeable fall in pitch from $2676 \mathrm{~Hz}$ to $1809 \mathrm{~Hz}$. N's non-committal tone and the falling pitch signal her intent to allow L to continue. Again, the overlap signals the ways in which the dynamics of languaging behaviour between persons reciprocally bind persons in states of intersubjective 
entanglement as they explore each other's dynamics on these rapid pico-scales and in doing so co-regulate each other's attention, perception, involvement, and awareness.

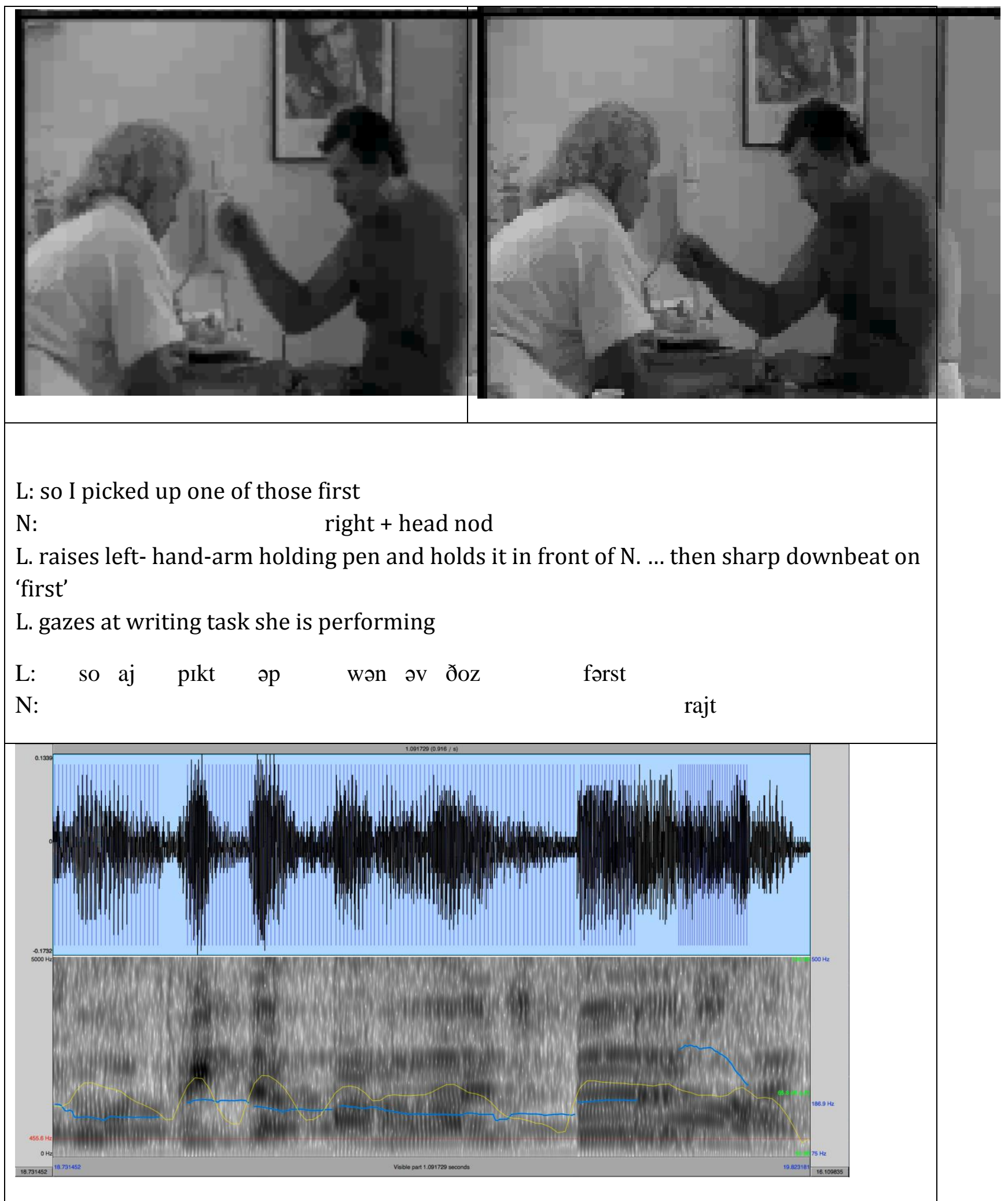

Figure 7: Pico-phase 4 


\section{Pico-phase 5}

L's utterance is characterized by a strong beat gesture, which coincides with third, which also receives emphatic stress. His gaze is directed at $\mathrm{N}$ during his emphatic, rapid delivery of this utterance. L's attention remains focused on the writing task, thereby sustaining the same postural orientation described in relation to Figure 7 above. On conclusion of his utterance, $\mathrm{L}$ begins a shift in orientation towards to the pen rack on his right.

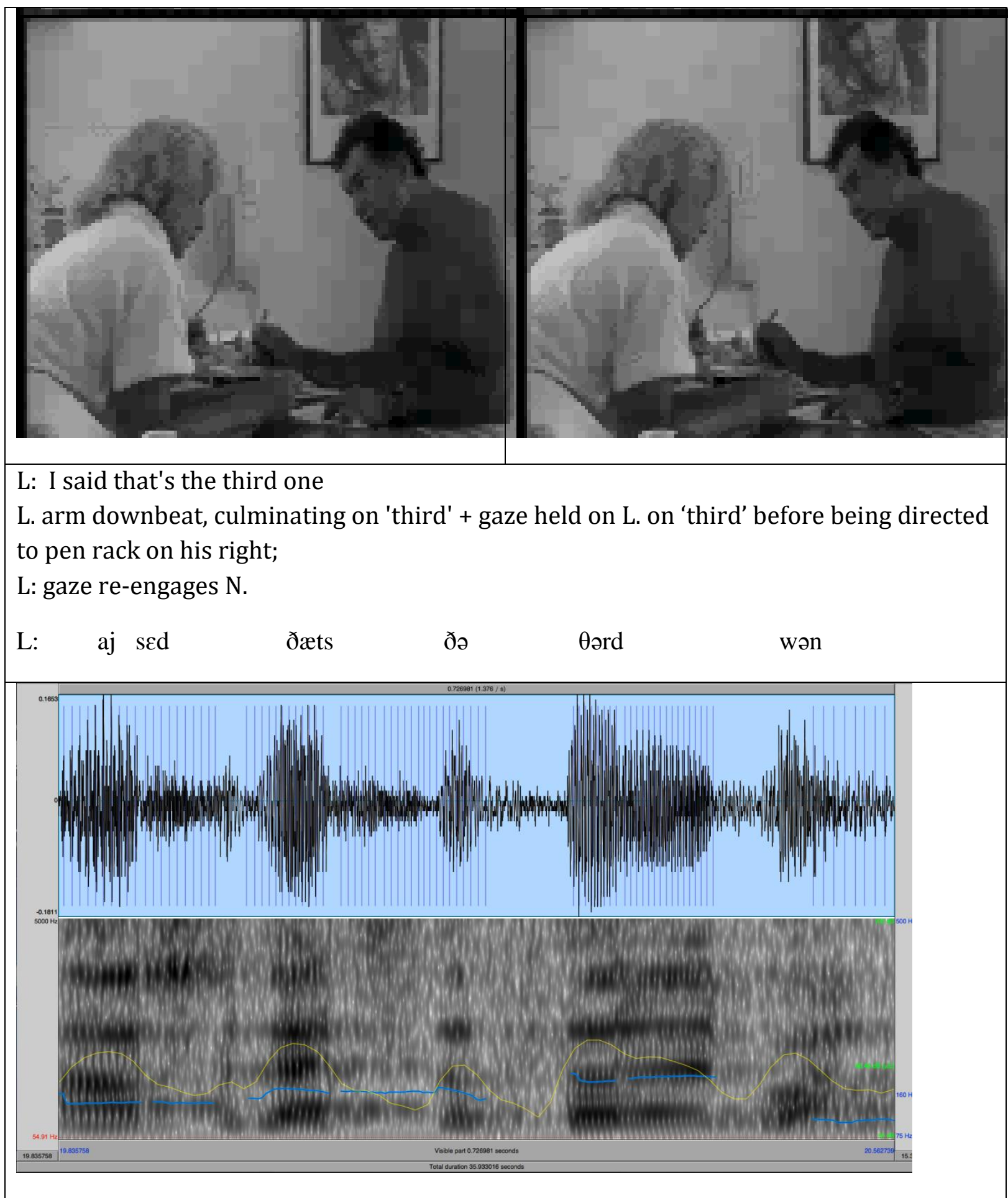

Figure 8: Pico-phase 5 


\section{Pico-phase 6}

During this utterance, L shifts orientation to the pen rack as his right arm, head, gaze and upper body orient to the pen rack whilst he reaches towards it to replace the pen he was holding. N's head and gaze turn left to track this shift in L's orientation. During the latter part of his utterance (hear me say that), his head turns briefly back to L in order to re-establish more direct interpersonal contact with her in a brief surge in intensity that this head movement captures. Also noteworthy is the higher energy level and therefore the increased salience of say along with the surge in pitch that L's uttering of say evidences. The initial pitch of this utterance is around 856.4 and at the end drops to $444 \mathrm{~Hz}$ after reaching a high of $1311 \mathrm{~Hz}$ at the beginning of say.

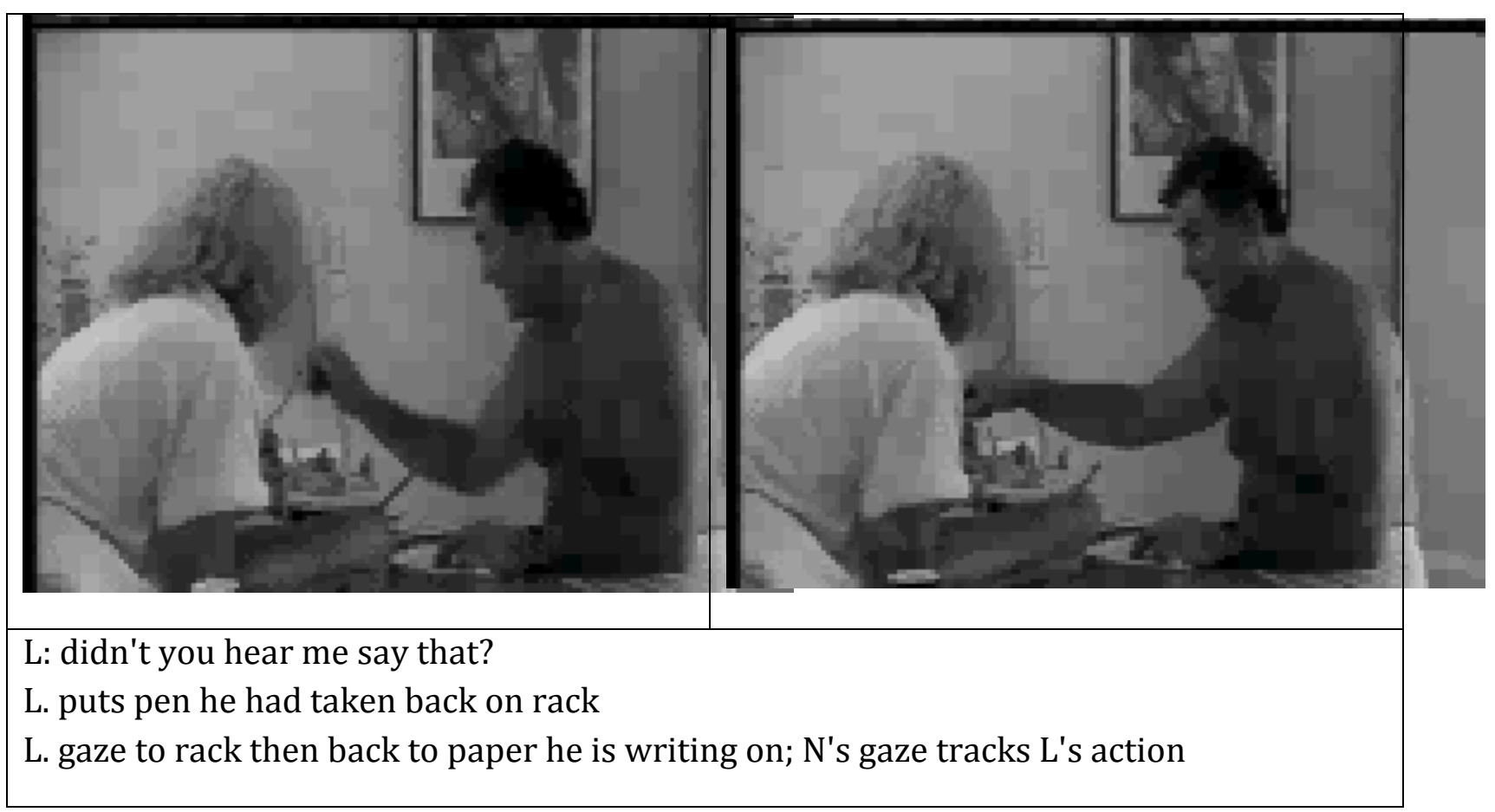




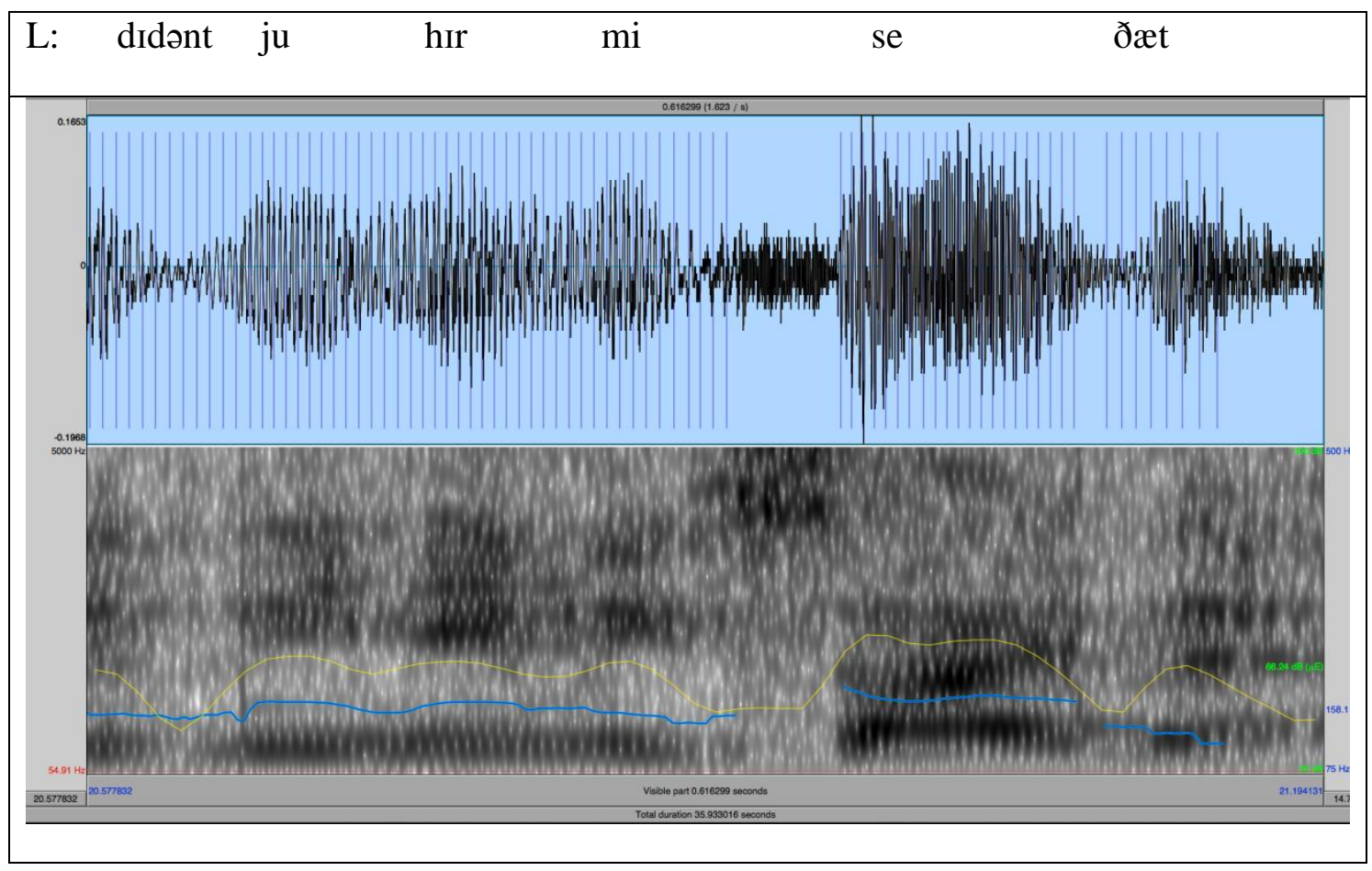

Figure 9: Pico-phase 6

\section{Some Further Implications of the Analysis}

We do things with our voices and other bodily movements that have the capacity to affect others. In minding and en-minding others with our voices we perform actions. The voice gives us access to others because we can change them with our voice and its many possibilities for modulation and differentiation. In the code view, we think of the voice as an encoder of ideas or meanings that we only have indirect access to. However, vocalizing is, above all, action that can move and change others. The direct effects upon the world that our voices can exercise are thus able to influence the indirect cognitive access we have that is dependent on neural coding. Voices extend our agency and our worlds because their direct, material agency brings about changes in others that in turn have the capacity to change our understandings of the world. It is this direct contact (e.g., the voice, the hands, and so on) that gives us our grip on the world and renders our ideas and understandings veridical. It is through this direct contact with and acting on the world that our more abstract ideas and understandings are enhanced.

First-order languaging as in vocalizing and related behaviours is a process of orienting both addressee and addresser. Both interpreting agents orient to and experience the integration of bodily activities and lexicogrammatical formats and patterns which are assembled and harnessed as a dynamic time-bound trajectory. The resulting meanings are distributed between all of the agents (addressers, addressees, observers) and vary according to the feeling states of the individual's body, the perspectives and psychological situations of the 
participants, their personal histories and concomitant experiences, and their perceptions and understandings of the circumstances in which the languaging behaviour takes place. Meaning is an emergent and variable process which does not correspond to an external reality, but is constantly negotiable and able to be adjusted in order that some kind of working agreement, however contingent and context-bound, about what is meant, can be arrived at. Languaging is a means of attending to experience in concerted fashion with either others or with the self in ways which afford ways of responding to and transforming the situation, including felt bodily responses to it, by providing the possibility for increased specification of the experience to be articulated. These processes take place across many different bodily and extra-bodily scales.

For example, the dynamics of the speaker's voice may provoke in the listener physiological responses (e.g., tensed muscles) which are felt by the addressee as feeling states of the body that provide implicit evaluations of and potential responses to the situation. Voice prosodies such as perceived patterns of rhythm, tempo or pacing, intonation (tone) and degree of loudness afford ways of synchronizing with the rhythms of the speaker and in achieving arousal, affective attunement, interpersonal harmony or convergence, and so on. Interindividual patterning of this kind thus constitutes a mutual form of body-sensing and bodyattunement that can bring about a qualitative shift in the experiences of the interlocutors. Prosodies also interact with and are integrated to lexicogrammatical units in various ways to signal salience, contrast, modal stances, and so on. They can, therefore, bring about a qualitative shift in participants' perceptions and understandings of lexicogrammatical units along with the referent situations that they construe. Phono-semantic operators (morphemic sub-markers) (Bottineau 2007:55) enact forms of deictic sensing and orientation that anchor the situation in felt bodily experience and the reference points attached to that. Wordings couple deictically grounded felt experience to the historically accumulated cultural experience of a population and the networks of associations, norms, and values (individual, social, and cultural) that wordings evoke by apperceptively matching current experience with previous experience, including felt bodily experience.

Meaning is not the starting point of this process, but is its emergent and always distributed achievement. Languaging is a form of exploratory activity that is oriented to the achieving of meanings, to making them emerge in the temporal flow of the activity itself. Languaging is a way of completing what was partially implicit, in the process transforming the nature of the situation and the values and understandings of its participants, though by no means in identical ways for all the persons involved. Emergent meanings do not reflect the situation, but dynamically transform it in the process of activating concerted thinking between participants. Meanings are crystallized in this process rather than being the preformed and static inputs to operations of encoding and decoding.

\section{The Quantum Coherence of Whole-body Sense-making and the Ontology of Entanglement}

Through first-order languaging we become entangled with and interwoven with each other's bodies and bodily feelings. The study of conversation has for the most part focused on verbal patterns and other abstracta such as discourse moves, conversational turns, and so on. Oddly, 
bodies and their articulatory capacities are seen as the encoders and transmitters of these abstracta. Linguistic and discourse-analytical approaches talk in terms of addressers/addressees, senders/receivers, or at best in terms of speakers/listeners. In these conceptions, addressers/addressees, senders/receivers, and so on, are local points in spacetime, reflecting the metaphysical premises of classical physics. These approaches remove the life from languaging.

With the exception of the latter pair of terms, none of these terms accounts for the ways in which languaging is not simply or only heard and seen; it is also felt. First-order languaging is a felt whole-body experience. Languaging is underpinned by the always dialogical, enkinaesthetic, entanglements of agents with each other (Stuart and Thibault Forthcoming). Bodily feelings, neurohormonal flows, blood pressure, galvanic skin response, physiological arousal and response, bodily displays, and action tendencies, to varying degrees of intensity, are synchronized as organized affective and bodily responses of whole living beings to each other. Such responses are reciprocal though not usually or necessarily symmetric. Your display of anger towards me does not mean ipso facto that I too will feel anger towards you. I may do so, but I may also instead feel shame, embarrassment, humiliation, etc.

Experimental psychologists have investigated the link between language comprehension and activation of the neural substrates of action and emotion (Gallese, et al., 1996; Gallese, Keysers \& Rizzolatti, 2004; and Rizzolatti, et al., 1996). When it comes to language, these approaches have focused on the same kinds of abstracta referred to above, viz. lexicogrammatical patterns. In one such experiment conducted by Mouilso et al (2007), participants were asked to read "angry, sad or neutral sentences to decide if the sentences made sense" (Mouilso et al 2007: 1326): "Sense judgments are made by moving a lever (see Figure 4) so that the time taken to move the lever can be used as a behavioral measure of the level of bodily activation associated with the emotion produced by the sentence." (Mouilso et al 2007: 1326) These approaches may tell us something about the ways in which second-order language has the potential to constrain and trigger enkinaesthetic responses. Thus, the cultural values and connotations that are evoked by particular lexicogrammatical patterns and their associated value-stances can trigger bodily feelings (Thibault 2005a: 288-299).

However, my concern in this paper lies in articulating an alternative to mechanistic views of talk that abstract away from body dynamics. Such views have predominated in conversation analysis and in discourse analysis. In these approaches, discourse-analytical or conversation analytical units such as 'moves' and 'turns' are said to be combined into sequences on the basis of rule-governed regularities that remove language from felt experience and personal history (Section 1). From the present perspective, these approaches fail to see that languaging is grounded in dialogically coordinated pico scale bodily events that are not merely heard and seen. They are also felt and sensed as whole-body experiences and feeling states (Cowley 2006). The fact that languaging is intimately and intrinsically connected to bodily feelings and sensations and the evaluations of situations that persons make about their own and other's feelings is of course entirely unaccounted for in these approaches. However, languaging just is whole-body sense-making. I argue that this felt dimension is absolutely fundamental to our 
experiencing and interpretation of first-order languaging (and much more). This view is supported by the experimental research of Gick and Derrick (2009), which showed that the neural processing of speech integrates naturalistic event-relevant tactile information during auditory speech perception.

Schrödinger's (1983 [1935]) used the term 'entanglement' to describe how two physical systems that enter into physical interaction with each other can never be the same again, even after they have separated, owing to the reciprocal influence of the one on the other (Schrödinger 1935: 555). The two systems thus become, according to Schrödinger, "entangled". In making this point, I am drawing on one of the fundamental lessons of contemporary physics to the effect that the coupling of microscopic quantum events to macroscopic ones means that the microscopic will affect the macroscopic. This is very different from saying that speakers and listeners, in their languaging, are atomistic monads (individuals) that are reducible to more and more micro states and properties on ever small scales, or that they encode, 'transmit' and 'decode' information or meanings to and from each other.

In the case of human interaction, the earlier work of Condon and Ogston (1966) and Condon (1970); see also Condon and Sander 1974), using high speed sound film techniques to analyse the flux of interactional behaviour between persons, showed that the assumption of discrete behavioural units that exist or occur "within and between the behaviour of individuals" (Condon and Ogston 1966: 338) does not hold. Instead, the very material nature of interaction dynamics transformed this into a recognition of what these authors called ""patterns of change" within ongoing behavior" (1966: 338). To quote Condon and Ogston:

Intensive analysis revealed harmonious or synchronous organization of change between body motion and speech in both intra-individual and interactional behavior. Thus the body of the speaker dances in time with his speech. Further, the body of the listener dances in rhythm with that of the speaker!

(Condon and Ogston 1966: 338)

The theory of mirror neurons is pertinent here. Mirror neurons connect observation and behaviour. Italian researchers Gallese, Rizzolati and Arbib, Fogassi, Fadiga, and others discovered mirror neurons, at the University of Parma, Italy in the 1990's. These researchers discovered that mirror neurons are activated both when someone observes another individual carrying out an action perceived to be intentional and when the same person carries out the same action. Mirror neurons are, in part, the neurological substrate for understanding and predicting another's observed actions. They suggest a relationship between observation of the behaviour of others and our understanding of it, including the ability to imitate others. In suggesting that the other is virtually present in our brains, we are able to relate to and empathise with the embodied perspectives of others as well as understand and anticipate others' intentions. Infants quickly pick up the vocal, facial, and other body actions associated with languaging. In observing and attending to the languaging behaviour of others, infants' neuronal activity builds connections between the motor cortex, perceived positions and 
movements of the articulators (lips, tongue, etc.) and the pick up through observation of auditory, visual, kinesic, and other information of the other person's vocal tract, facial and other movements.

First-order languaging is a form of concerted activity between persons. It promotes the forms of observation and attendant emotional involvement or empathetic attachment that lead to the activation of the observer's premotor system in the frontal cortex. In this way, the patterns of neuronal activation that occur prime or ready the observer for the action though without necessarily entailing that the observer carries out the observed action. Mirror neurons allow us to co-participate in, or to co-author, virtually speaking, the other's actions without actually performing the action in question (Bråten 2007). In this sense, they may play a role in the forms of concerted rehearsal discussed in Section 3. The observation of another's actions does not, therefore, automatically translate into the observer's execution of a similar action. Languaging is a form of rehearsal in which the extremely fine-grained differentiations made by co-articulated vocal tract gestures and prosodies enable others to recreate in their neural activity similar patterns. Such patterns enable observers to perceive or to simulate an understanding of the other's meanings and perspectives from the observer's own perspective. The concerted nature of languaging also means that languaging agents are entrained to similar, not necessarily identical, patterns. Agents accordingly develop shared expectations as to what the observed behaviours are.

The focus on verbal abstracta and the concomitant failure to provide a naturalistic grounding to languaging behaviour has led to the neglect of the temporal dimension of language behaviour. Timing not just time (let alone clock time) is crucial here, as is rhythm. Coconstructed interaction between two (or more) agents crucially involves timing. The neurological dynamics of the brain function as a system of oscillating processes on very many time scales. Many aspects of observable language dynamics occur on very fast scales. The notion of pico-scale bodily dynamics has been developed to demonstrate the centrality of very short or rapid time-scales that are involved in many aspects of vocalizing, eye movements, rhythm, tone, gesture, and much more. These phenomena are not readily captured by conventional analysis and transcription. These descriptive methods focus on second order abstracta of the kind that linguistics over the past 100 years has specialized in documenting.

Crucially, the central nervous system is a system of oscillators and the modulatory relationships between oscillators. Neurons and neuron circuits are oscillatory and are modulated by influences from other neurons and neuron circuits in distributed networks of brain activity. These, in turn, coordinate the pico-scale bodily dynamics that are coorchestrated as emergent, inter-individual dynamical patterns when two or more agents cosynchronize their neural and bodily dynamics in dialogically coordinated interaction. Oscillators have the functional capacity to synchronize with and entrain to one another's behaviour (DeLanda 2002: 92). In a population of interacting agents, the capacity to synchronize and entrain to other agents and to other, non-human individuals (e.g. environmental affordances) on different spatio-temporal scales allows for the coordination of internal biological rhythms and external social ones (see also Lefebvre 2004 [1992]: 38-45). 
In a population of interacting agents, synchronization is catalyzed by signals -- e.g. optical, chemical, mechanical (DeLanda 2002: 93), auditory, etc. - whose intensity must be maintained at a critical threshold for the synchronization to be maintained over a given time span.

To successfully manage their interaction, agents-in-interaction must co-entrain their neural circuitry and bodily dynamics into a synchronous time-locked behavioural dance. Interactants attune to each other's body dynamics on the pico-scale as a coupled system. What Buzsáki (2006: 8) calls the "feeling of time" of human agents ranges from tens of milliseconds to tens of minutes. It is this time span, according to Buzsáki, which corresponds to the "temporal range of brain oscillators, which may serve as an internal metric for time calibration" (Buzsáki 2006: 8). The best human time resolution is in the sub-seconds range, which corresponds to the pico-scale of the co-constructed bodily dynamics that are central to firstorder languaging. Neuronal oscillations related to pico-scale bodily dynamics are crucial to the functioning of languaging (Section 31).

The brains and bodies of individual persons have the capacity to enter into co-synchronous patterns by changing their rhythm so as to converge over a given time span on a common or inter-individual pattern of rhythmic activity. Neurons have different frequencies, which are utilized to pull each other to a synchronized pattern. The stimulation of particular brain regions gives rise to synchronous patterns as various neuronal groups converge on the common pattern. In this way, individual brain structures are created when they synchronize to form coherent neural circuits that create rhythmic oscillations known as brain waves. These observations apply on the intra-individual level and lend support to the earlier research of Condon and Ogston (1966) regarding the "harmonious or synchronous organization of change between body motion and speech" on the intra-individual level. As pointed out above, these researchers also observed these same effects on the interactional or inter-individual level when, for example, two or more persons engage in conversation. It is now known that in interpersonal interaction, persons co-adapt and co-adjust to each other's bodily and neuronal rhythms.

Again, as Condon and Ogston (1966) showed, participants in conversation synchronize their bodily rhythms and movements with one another. They enter into a "resonance pattern" (Hart 2008 [2006]: 83). Research on mirror neurons suggests that oscillating neurons coordinate the interactive dance of neural and bodily dynamics that occurs between persons in conversation. Thus, two or more individuals who are participating in interactional synchrony give rise to resonance patterns that are inter-individual in character. These can vary in duration and intensity. The flow of energy between the body-brain systems of the two (or more) individuals means that novel patterns arise as the two agents co-regulate each other. Researchers in this area have used terms such as "affective attunement" or "intersubjective awareness" to explain the co-regulation of feeling, affect, perception, action and cognition that takes place when inter-individual synchronization occurs. Moreover, mirror neurons explain the ability to connect observation and behaviour in ways that indicate that the other 
persons with whom one interacts are "represented" in one's patterns of neuronal activity (Hart 2008 [2006]: 90).

In the present account, I would argue that we do not so much 'empathise' with others in the way that Hart and others have suggested; we become entangled with each other's neural, affective, and bodily dynamics. The notion of 'empathy' continues to promote an individualistic model in which one freestanding person empathises with another, as shown in the usual discussion of the theory of mirror neurons. In this theory, other persons' feelings, intentions, and states of mind are said to be re-created in the neural activity of the observer through processes called mirroring (Hart 2008 [2006]: 91). Hart (2008 [2006]: 92) cites a study by Ekman (2003) who conducted experiments on mood changes in relation to the activation of certain facial muscles. This research shows that if "someone contracts the same facial muscles as the other person, he or she senses the other's emotion" (Hart 2008 [2006]: 92). Hart points out that this is not imitation. Instead, empathetic attunement is achieved on the basis of external gestures, vocalizations, and body movements that activate the mirror neuron circuits in the observer such that the observer can sense another's feelings, moods, intentions, and so on. Infants thus learn to integrate the other's feelings, moods and states of mind through the observation and perception of the other's gestures, facial expressions, and vocalizations in order to achieve affective and other forms of attunement

One problem with this view - for example, that other persons are "represented" in patterns of neuronal activity - is that it does not account for the ways in which interpretation of each other arises as agents perceive, feel and engage with each other's feelings and neural and body dynamics in real-time. Moreover, as stated above, the emphasis remains on individuals who attune to, empathise with, and represent each other. Individuals are still assumed to be separately existing localized entities that are externally related to each other by space and time. I would rather say that, ontologically speaking, individual persons are not definable independently of the nexus of relations and dynamical fields in which they are entangled with others, neurally and bodily. To use a Heiddergerian turn of phrase, we are with each other in our Mitwelt (Stuart and Thibault Forthcoming). In particular, for the purposes of this paper, agents are entangled in dialogically coordinated social events and communities that are controlled by the brains and bodies of the diverse participants in those events. Such events are not controlled by rules that govern the sequential unfolding of interaction, seen as a series of moves or turns of the kind that are typically featured in discourse-analytical and conversation-analytical approaches to talk (Hodges 2009; Thibault 2008, 2011). These analytical constructs cannot capture the very small temporal scales of the bodily dynamics that are important here. Persons in interaction actively engage with the other's feelings at the same time that the actions (e.g. vocal dynamics, facial expressions, gestures) of the other prompt us to act and to feel in ways that alter the 'feeling of what happens' (Damasio 1999, 2005) between and within persons.

Dialogically coordinated social events make use of pico-scale bodily dynamics that connect people in ways that we interpret as meaningful. Rather than viewing the relationship between self and other as an opposition between subject and object, as in the Cartesian tradition, I 
would invoke Heidegger's concept of Dasein. In Heidegger's conception, the crucial feature of Dasein is it's being with the world, being involved with it, being concerned for its world. In agreement with Heidegger, Stuart and Thibault (Forthcoming) argue that the enkinaesthetic enfoldings of agents with their worlds constitute the primordial pre-conceptual understandings that are the very "thrownness" - the term is Heidegger's -- of agents in terms of which all understanding and interpretation between agents and their worlds are created. It is the primordial way of encountering and experiencing the world of new-born infants that enables then to find their way in and with the world, as evidenced in the earliest forms of enkinaesthetic enfolding between parents and new-born infants.

Pico-scale events are bodily dynamics that typically occur on time-scales in the order of fractions of seconds to milliseconds. They are real patterns of inter-individual behaviour though they are not representational patterns: on the time and space scales of human interaction, they enable agents to keep track of both others' and the agent's own concernful engagements with aspects of their worlds. The fact that both pre-linguistic babies and some other species are able to track aspects of selves and others on the basis of such patterns shows that they are not linguistic patterns in the sense that 'language' is usually understood though, as I argue in this paper, they are dynamical patterns that are absolutely fundamental to the workings of first-order languaging. For instance, we humans use words like "embarrassment", "anger", "desire", and so on, as second-order (linguistic) descriptors to index aspects of these patterns which we take to be cognitively, affectively, and interpretatively salient at the community level.

On both the phylogenetic and ontogenetic time scales, such linguistic descriptors are secondorder patterns with respect to the first-order patterns of the pico-scale dynamics for contingent historical reasons. On the scale of real-time interaction between persons, patterns on the scale of the pico-scale dynamics are first-order in the sense that they are not representational with respect to any other level. They are, however, real patterns that people respond to, interpret and talk about even though they are, for many people, often much harder to talk about than second-order (linguistic) patterns though this does not mean that they cannot talk about them. What is perhaps most significant is that our concernful enactment of and engagement with these (first-order) dynamical patterns, in enabling persons to move each other and to be moved by others, prompts or gives rise to interpretation. For example, in saying that we feel the anger in someone's voice, or that someone spoke in a friendly voice, and so on, we are responding to some aspects of a real inter-individual pico-scale pattern and attributing it to the properties of individuals (e.g. properties of self and/or other in some interactive encounter).

According to the metaphysic lurking in the ontological shadows of this account, we are treating some aspects of the real patterns so identified as properties of individual agents (e.g. 'Harry is angry'; 'I feel sad'). Following Dennett (1991) and Ladyman and Ross (2007: 243), I would further argue that insofar as and to the extent that these second-order descriptors correctly approximate real patterns we can say that the descriptors endorse a standard metaphysics of individuals as real entities while at the same time failing to correctly account for the ontological status of the real patterns. In other words, individual agents in this 
metaphysic are "locators" - the term is from Ladyman and Ross (2007: 243) - for aspects of interactional patterns that we use to keep track of always changing inter-individual interactional dynamics that cannot be correctly correlated with individual behaviours or perspectives per se owing to a history of entanglements between the temporal trajectories of selves-in-interaction (Thibault 2004a, 2004b). This shift in perspective requires an ontology of enfolding or entanglement (Stuart and Thibault Forthcoming). Persons are not skin-bound discrete locators occupying different localized regions of time and space. They are instead temporally unfolding trajectories in a field of mutually overlapping and enfolded affective and other dynamical patterns of reciprocal engagement between trajectories-in-time.

Oscillatory neuronal networks (Sections 3, 6, 14) also imply nonlinear time: simultaneity of oscillations, rather than one event preceding another and hence 'causing' it. Many open questions can be raised at this point: How do human interactants perceive and chunk the perceived body dynamics of self and other? These processes depend on time and timing. How are brain-constructed time and external time different from the points of view of different persons? What are the implications of this for the ways in which humans interact and become 'entangled' with one another's neural and bodily dynamics? How do the (different or convergent?) ways of constructing past experience of persons impinge upon the ways in which co-synchronous brains in interaction co-construct experience? How do the complex, multilevel circular processes of causation involved in the co-constructed dynamics of two (or more) brains in reciprocal interaction modify and complicate our understandings of the oscillatory and modulatory dynamics of brains in real-life biological agents interacting with each other and with aspects of their worlds?

Stuart and Thibault (Forthcoming) propose the neologism 'enkinaesthetic' because trajectories of agents, unlike "chunks of Cartesian space", can, to varying degrees of felt intensity and duration, 'occupy' the same temporal-spatial-energic-semantic field. In this, we are at one with the concept of eidetic field that has been put forward by biologist, Anton Markoš (2002: 69):

Understanding, orientation, discovering new possibilities is knowledge gained by interpretation -that is, a genuine hermeneutic feat. Eidetic biology understands life processes precisely in these terms. It views living beings as eidetic spaces or semantic fields of formative causation. Like knowledge and learning, development and evolution are based on the interpretation of the embodied living experience stored as eidos, that is, as a specific formative strategic way of formation -information, interpreted by imitation within the current context.

At first glance, such an approach to living beings as mindlike existences might seem to be in sharp contrast to the traditional view, according to which the bodily existence is reducible to a particular composition of material parts filling the inert geometrical space. For eidetic biology, the elements of life are elements of meaning rather than chunks of Cartesian space: a mechanism is merely a projection of eidos into a geometrical space. But any mechanism is by definition an eidos (purpose, strategy, instruction) implemented in a special way of mechanistic causation (as an abacus is an 
implementation of numbers into strings of beads). To make use of a device -mechanical or not-means to understand it.

(Markoš 2002: 69)

Rather than "chunks of Cartesian space" that send coded messages to each other across the empty space that separates the respective chunks, persons are living, moving, and feeling beings who inhabit a dynamical field of energies, relations, reciprocities, meanings, and interpretations. It is through meaning and interpretation that they relate to and connect to their worlds through being enfolded with the neural, affective, and bodily dynamics of each other in a community of reciprocal enfoldings between agents and between agents and objects. Living beings are coherent systems that are "synchronized through many levels of organization" (Markoš 2002: 105) from the most microscopic to the most macroscopic. The essence, if you like, of whole-body-sense-making lies in the way in which meaning-making is not localized at particular articulators such as the vocal tract, but involves, on the intraindividual level identified by Condon and Ogston (1966), many different size scales from the molecular to the whole organism. The travelling wave of a phonetic gesture unifies feeling, perception and action in the whole organism such that response time is immediate (Hollis, Kloos and Van Orden 2009: 213); feeling, perception and action occur on such rapid timescales extending to the most primordial layers of core consciousness (Section 11) that there can be no time for information processing or encoding/decoding. The fractal coupling of travelling waves at all levels of the organism (Davia 2006) suggests that organisms are coherent systems at all levels of organization in ways that allow for and are characterized by "high-efficiency energy transfers with minimum loss." (Markoš 2002: 105). Markoš discusses the work of another biologist, Mae-wan Ho (1993, 1994), in order to shed light on the coherence, synchronization and nonlocal nature of the organization of living beings as "selfstructuring fields" (Markoš 2002: 104) across all scalar levels of their organization in contrast to the chemical kinetics of nonliving systems. To quote Ho:

Intercommunication can proceed so rapidly through the liquid crystalline continuum of the organism that in the limit of the coherence time and coherence volume of energy storage - the time and volume respectively over which the energy remains coherentintercommunication is instantaneous and nonlocal. There is no time-separation within the coherence volume, just as there is no space-separation within the coherence time. Because the organism stores coherent energy over all space-times, it has a full range of coherent space-times, which are furthermore, all coupled together. (p. 93)

(Ho 1988: 93; quoted in Markoš 2002: 106)

The coherence in living beings is, as Ho (1988, quoted in Markoš) and Markoš (2002: 106) argue, quantum in nature. Living organisms are accordingly interpreted as "highly coherent systems interconnected through many orders of space $\left(10^{-10}\right.$ to $\left.10^{1} \mathrm{~m}\right)$ and time $\left(10^{-14}\right.$ to $10^{7}$ s)" (Markoš 2002: 106). According to Ho: 
One comes to the startling conclusion that the coherent organism is a macroscopic quantum object. It has a macroscopic wavefunction that is always evolving, always changing as it entangles its environment. This wavefunction is the unique, significant form of the organism.

(Chang et al 1998: 94; quoted in Markoš 2002: 106)

Sense-making is a macroscopic energic-semantic wave function of the whole living being -i.e. across all scales of its being --in concert with that being's world. Whole body-sensemaking involves the quantum coherence of the entire organism. Whole body-sense-making cannot be localized as the outputs or inputs of particular performatory or receptive systems of the body such as, for example, the vocal tract and the sense receptors. The idea of entanglement, mentioned above, suggests that individuals become entangled with each other at the organismic level on the basis of their "macroscopic wave function that is always evolving, always changing as it entangles its environment" Chang et al 1998: 94; quoted in Markoš 2002: 106). The wave function of living beings is a dynamical temporal pattern or "kinetic melody" (Luria 1973: 32, 36; Stuart and Thibault Forthcoming) of bodily action and feeling that is the "unique signature" of the individual. Ho (1988) and Chang et al (1998) thus interpret organisms as macroscopic quantum objects.

Ho therefore postulates that the coherence of living beings is quantum in nature (Markoš 2002: 106). This means that the characteristics of quantum physics are not confined to the microscopic domain; they are coupled to the macroscopic world, meaning that quantum effects also pervade the macroscopic domain, as Ho's postulate concerning the quantum nature of living beings suggests. There can be no return to the notion that living beings are just "chunks of Cartesian space" that can be defined in terms of the ever smaller components out of which they are composed, as in the classical model. All organizational scales of living beings are implicated in whole body-sense-making. Whole-body-sense-making is a projection of the quantum coherence of the whole living being in concert with its world.

The earlier findings of Ho resonate well with those of Davia, discussed above (Section 13). The essentially instantaneous and nonlocal character of the intercommunication across all fractal levels of the organism's quantum coherence means that the whole organism is an excitable medium of coherent space-times on different fractal levels, all of which are fully coupled. Language activity is whole-body-sense-making. It is truly immediate and works over the whole range of the wavelengths of the body's quantum coherence to yield a global, nonlocal bodily response as agents catalyze their worlds in and through their dialogically coordinated languaging behaviour. 


\section{References}

Abler, William (1989). On the particulate principle of self-diversifying systems. Journal of Social and Biological Structures 12: 1-13.

Alač, Morana and Hutchins, Edwin (2004). I see what you are saying: action as cognition in fMRI brain mapping practice. Journal of Cognition and Culture 4:3: 629-661.

Allen, Jedediah W. P. and Bickhard, Mark H. (2011). Normativity: A crucial kind of emergence: Commentary on Witherington. Human Development 54: 106-112.

Argyropoulos, Giorgos P. (2008). The subcortical foundations of grammaticalization. In: A. D. M. Smith, K. Smith, and R. Ferrer i Cancho (Eds.), The Evolution of Language: Proceedings of the 7th International Conference on the Evolution of Language. Singapore: World Scientific Press, pp. 10-17.

Arndt, Horst and Janney, Richard Wayne (1987). Intergrammar: Towards an integrative model of verbal, prosodic and kinesic choices in speech. Berlin and New York: Mouton de Gruyter.

Baldry, Anthony and Thibault, Paul J. (2006). Multimodal Transcription and Text Analysis: A multimedia toolkit and course book (with associated online course). Foreword by Jay Lemke. London, UK and Oakville, CT: Equinox.

Barbieri, Marcello (2003). The Organic Codes: An introduction to semantic biology. Cambridge, UK: Cambridge University Press.

Bickhard, Mark H. (1998). Levels of representationality. Journal of Experimental and Theoretical Artificial Intelligence 10: 179-215.

Bickhard, Mark H. (2004). The dynamic emergence of representation. In: H. Clapin, P. Staines, P. Slezak (Eds.), Representation in Mind: New Approaches to Mental Representation. Amsterdam, The Netherlands and Boston, MA: Elsevier, pp. 71-90.

Bickhard, Mark H. (2008). Social ontology as convention. Topoi 27(1-2): 139-149.

Bottineau, Didier (2007). The cognemes of the Spanish language: Towards a cognitive modelization of the submorphemic units in the grammatical words of the Spanish language. The Public Journal of Semiotics I(2), July 2007: 50-74.

Bouissac, Paul (2006). The optic, haptic, and acoustic dimensions of gestures: evolutionary significance and methodological implications. Berlin Gesture Center, Interdisziplinäres BGC-Kolloquium Freitag, 10. November 2006;

[http://www.semioticon.com/people/articles/Gesture.htm]; downloaded $2^{\text {nd }}$ October 2010.

Bouisssac, Paul (2010). Saussure: A guide for the perplexed. London and New York: Continuum. 
Bråten, Stein (2007). Altercentric infants and adults: On the origins and manifestations of participant perception of others' acts and utterances. In: Stein Bråten (Ed.), On Being Moved: From mirror neurons to empathy. Amsterdam/Philadelphia: John Benjamins, pp. 111-135.

Bråten, Stein and Trevarthen, Colwyn (2007). Prologue: from infant intersubjectivity and participant movements to simulation and conversation in cultural common sense. In: Stein Bråten (Ed.), On Being Moved: From mirror neurons to empathy. Amsterdam/Philadelphia: John Benjamins, pp. 21-34.

Browman, Catherine P. and Goldstein, Louis (1992). Articulatory phonology: an overview. Phonetica 49: 155-180.

Browman, Catherine P. and Goldstein, Louis (1995). Dynamics and articulatory phonology. In: Robert P. Port and Timothy van Gelder (Eds.), Mind as Motion: Explorations in the dynamics of cognition. Cambridge, MA and London, UK: The MIT Press, pp. 175-193.

Browman, Catherine P. and Goldstein, Louis (2002). Articulatory Phonology. Draft: Chapter 1, Speech production actions as phonological primitives. [http://sail.usc.edu/ lgoldste/ArtPhon/Papers/Week\%201/AP_ch1.pdf], downloaded: $22^{\text {nd }}$ November 2011.

Buzsáki, György (2006). Rhythms of the Brain. Oxford and New York: Oxford University Press.

Bybee, Joan L. (1998). A functionalist approach to grammar and its evolution. Evolution of Communication 2: 249-278.

Bybee, Joan L. and Thompson, Sandra A. (2000). Three frequency effects in syntax. Berkeley Linguistic Society 23: 65-85.

Cassell, Justine and Tartaro, Andrea (2007). Intersubjectivity in human-agent interaction. Interaction Studies 8(3): 391-410.

Chang, Jiin-Jiu, Fisch, Joachim, and Popp, Fritz-Albert (Eds.), (1998). Biophotons. Dordrecht: Kluwer.

Carpenter, Patricia A. and Davia, Christopher J. (2006). A catalytic theory of embodied mind. http://csjarchive.cogsci.rpi.edu/proceedings/2006/docs/p1080.pdf. Downloaded: 12th May 2011.

Clark, Andy (1997). Being There: Putting brain, body and world together again. Cambridge, MA: The MIT Press.

Clark, Andy (2008). Supersizing the Mind: Embodiment, action and cognitive extension. Oxford: Oxford University Press. 
Condon, W. S., and Ogston, W. D. (1966). Sound film analysis of normal and pathological behavior patterns. Journal of Nervous and Mental Diseases 143: 338-457.

Condon, William S. (1970). Method of micro-analysis of sound films of behavior. Behavior Research Methods, Instruments \& Computers 2(2): 51-54.

Condon, William S. and Sander, Louis W. (1974). Neonate movement is synchronized with adult speech: interactional participation and language acquisition. Science 183 (January 1974): 99-101.

Corballis, Michael C. (2011). The Recursive Mind: The origins of human language, thought, and civilization. Princeton and Oxford: Princeton University Press.

Cowley, Stephen J. (2006). Language and biosemiosis: a necessary unity? Semiotica 162(1/4): 417-444.

Cowley, Stephen J. (2007). How human infants deal with symbol grounding. Interaction Studies 8(1): 81-104.

Cowley, Stephen J. (2007). Cognitive dynamics and distributed language. Language Sciences 29(5): 575-583.

Cowley, Stephen J. (2008). The codes of language: turtles all the way up? In: Marcello Barbieri (Ed.), The Codes of Life: The rules of macroevolution. Berlin: Springer, pp. 319-345.

Cowley, Stephen J. (2011). Taking a language stance. Ecological Psychology 23(3): 185-209. To link to this article: http://dx.doi.org/10.1080/10407413.2011.591272.

Cowley, Stephen, Moodley, S., and Fiori-Cowley, Agnese (2004). Grounding signs of culture: primary intersubjectivity in social semiosis. Mind, Culture, Activity 11(2): 109-132.

Damasio, Antonio (1999). The Feeling of What Happens: Body, emotion and the making of consciousness. London and Sydney: Heinemann.

Damasio, Antonio (2005). The neurobiological grounding of human values. In: J.-P. Changeux, A. R. Damasio, W. Singer, and Y. Christian (Eds.), Neurobiology of Human Values. Berlin and New York: Springer Verlag, pp. 47-56.

Damasio, Antonio (2010). Self Comes to Mind: Constructing the conscious brain. London: Heinemann.

Davia, Christopher J. (2006). Life, catalysis and excitable media: A dynamic systems approach to metabolism and cognition. In: Jack Tuszynski (Ed.), The Physical Basis for Consciousness. Heidelberg: Springer-Verlag, pp. 255-292.

Davidse, Kristin (1997). The Subject-Object versus the Agent-Patient asymmetry. Leuvense Bijdragen (Leuven Contributions in Linguistics and Philology) 86(4): 413-431. 
Deacon, Terrence W. (1996). Prefrontal cortex and symbol learning: why a brain capable of language evolved only once. In: Boris M. Velichkovsky and Duane M. Rumbaugh (Eds.), Communicating Meaning: The evolution and development of language. Malwah, NJ:

Erlbaum, pp. 102-138.

DeLanda, Manuel (2002). Intensive Science and Virtual Philosophy. London and New York: Continuum.

DeLanda, Manuel (2011). Deleuze: History and Science. New York and Dresden: Atropos Press.

Deleuze, Gilles and Guattari, Félix (1987). A Thousand Plateaus. Minneapolis, MN:

University of Minnesota Press.

Deleuze, Gilles 2004 [1968]. Difference and Repetition. Trans. Paul Patton. London and New York: Continuum.

Deleuze, Gilles (1994). Difference and Repetition. New York: Columbia University Press.

Demos, E. Virginia (1988). Affect and the development of the self: a new frontier. In: Arnold Goldberg (Ed.), Frontiers in Self Psychology: Progress in self psychology, Volume 3.

Hillsdale, NJ and London, UK: The Analytic Press, pp. 27-53.

Dennett, Daniel C. (1991). Real patterns. The Journal of Philosophy 88(1): 27-51.

Edelman, Gerald M. (1987). Neural Darwinism: The theory of neuronal group selection. New York: Basic Books.

Edelman, Gerald M. (1989). The Remembered Present. A biological theory of consciousness. New York: Basic Books.

Ekman, Paul (2003). Emotions Revealed. New York: Times Books.

Fontana, Walter and Buss, Leo (1996). The barrier of objects: From dynamical systems to bounded organizations. In: John Casti and Anders Karlquist (Eds.), Boundaries and Barriers. Reading, MA: Addison-Wesley, pp. 56-116.

Fowler, Carol A. (1986). An event approach to the study of speech perception from a directrealist perspective. Journal of Phonetics 14: 3-28.

Fowler, Carol A. (2010). Embodied, embedded language use. Ecological Psychology 22(4): 286-303. To link to Carol Fowler's Article: DOI: 10.1080/10407413.2010.517115; URL: http://dx.doi.org/10.1080/10407413.2010.517115

Freeman, Walter J. (1995). Societies of Brains: A study in the neuroscience of love and hate. Hillsdale, NJ and Hove, UK: Lawrence Erlbaum. 
Freeman, Walter J. (2000). How Brains Make Up their Minds. New York: Columbia University Press.

Gabora, Liane (2004). Ideas are not replicators but minds are. Biology and Philosophy 19(1): 127-143.

Gafos, Adamantios I. (2002). A grammar of gestural coordination. Natural Language and Linguistic Theory 20(2): 269-337.

Gafos, Adamantios I. (2006). Dynamics in grammar: comment on Ladd and Ernestus and Baayen. In: M. L. Goldstein, D. H. Whalen, and C. Best, (Eds.), Laboratory Phonology 8: Varieties of Phonological Competence. Berlin/New York: Mouton de Gruyter, pp. 51-79.

Galantucci, Bruno (2005). An experimental study of the emergence of human communication systems. Cognitive Science 29: 737-767.

Gallese, V., Luciano F., Leonardo F., and Rizzolatti, G. (1996). Action recognition in the premotor cortex. Brain 119: 593-609.

Gallese, V., Keysers, C., and Rizzolatti, G. (2004). A unifying view of the basis of social cognition. Trends in Cognitive Sciences 8: 396-403.

Garfinkel, Alan (1981). Forms of Explanation: Rethinking the questions in social theory. New Haven and London: Yale University Press.

Gibson, James J. (1977). The Theory of Affordances. Hillsdale, NJ: Erlbaum.

Gibson, James J. (1983 [1966]). The Senses Considered as Perceptual Systems. Boston: Houghton Mifflin.

Gibson, James J. (1986 [1979]). The Ecological Approach to Visual Perception. Hillsdale, NJ: Erlbaum.

Gick, Bryan and Derrick, Donald (2009). Aero-tactile integration in speech perception. Nature Vol. 462, November 2009: 502-504.

Goldstein, Louis M., Fowler, Carol (2003). Articulatory phonology: a phonology for public language use. In: Antje S. Meyer and Niels O. Schiller, (Eds.), Phonetics and Phonology in Language Comprehension and Production: Differences and Similarities, Berlin: Mouton de Gruyter, pp. 159-207. http://sail.usc.edu/ lgoldste/ArtPhon/Papers/Week\%201/GoldsteinFowler.pdf (Downloaded: 13 August 2011)

Goffman, Erving (1983). The interaction order. American Sociological Review 48: 1-17.

Halliday, M. A. K. (1975). Learning How to Mean: Explorations in the development of language. London: Arnold. 
Halliday, M. A. K. (1991). Towards probabilistic interpretations. In: Eija Ventola (Ed.), Functional and Systemic Linguistics: Approaches and uses. Berlin: Mouton de Gruyter, pp. 39-61.

Halliday, M. A. K. (2004 [1985]). Introduction to Functional Grammar. 3rd edition. Revised by Christian M. I. M. Matthiessen. London and Melbourne: Arnold.

Harris, Roy (1980). The Language Makers. Ithaca, New York: Cornell University Press.

Harris, Roy (1981). The Language Myth. London: Duckworth.

Harris, Roy (1990). On redefining linguistics. In: Hayley G. Davis and Talbot J. Taylor (Eds.), Redefining Linguistics. London and New York: Routledge, pp. 18-52.

Harris, Roy (2000.) Rethinking Writing. London: Athlone Press.

Harris, Zellig (1952). Discourse analysis. Language 28(1): 1-30.

Harris, Zellig (1991). A Theory of Language and Information: A mathematical approach. Oxford and New York: Clarendon Press.

Hart, Susan (2008 [2006]). Brain, Attachment, Personality: An introduction to neuroaffective development. London: Karnac.

Hart, Susan 2011 [2006]. The Impact of Attachment: Developmental neuroaffective psychology. New York and London: W. W. Norton.

Hasan, Ruqaiya (2009) [1992]). Rationality in everyday talk: from process to system. In: Jonathan J. Webster (Ed.), Semantic Variation: Meaning in society and in sociolinguistics, The collected works of Ruqaiya Hasan, Volume 2, London, UK and Oakville, CT: Equinox, pp. 309-352.

Ho, Mae-Wan (1988). On not holding nature still: evolution by process, not by consequence. In: M-W. Ho and S. W. Fox (Eds.), Evolutionary Processes and Metaphors. Chichester, U.K.: Wiley, pp. 117-114.

Ho, Mae-Wan (1993). The Rainbow and the Worm. Singapore: World Scientific.

Ho, Wae-Man (1994). What is (Schrödinger's) negentropy?. In: E. Gnaiger et al (Eds.), What is Controlling Life?. Innsbruck: Insbruck University Press, pp. 50-61.

Hockett, Charles D. (1960). The origins of speech. Scientific American 203: 89-96.

Hodges, Bert H. (2007). Good prospects: ecological and social perspectives on conforming, creating, and caring in conversation. Language Sciences 29: 584-604. 
Hodges, Bert H. (2009). Ecological pragmatics: values, dialogical arrays, complexity, and caring. Pragmatics \& Cognition 17(3): 628-652. doi 10.1075/p\&c.17.3.08hod issn 0929-0907 / e-issn 1569-9943.

Hollis, Geoff, Kloos, Heidi, and Van Orden, Guy C. (2009). Origins of order in cognitive activity. In: S. J. Guastello, M. Koopmans, and D. Pincus (Eds.), Chaos and Complexity in Psychology: The Theory of Nonlinear Dynamical Systems. Cambridge, MA: Cambridge University Press, pp. 206-241.

Hutchins, Edwin (1995a). Cognition in the Wild. Cambridge, MA: The MIT Press.

Hutchins, Edwin (1995b). How a cockpit remembers its speeds. Cognitive Science 19: 265288.

Hutchins, Edwin (2010). Cognitive ecology. Topics in Cognitive Science 2: 705-715.

Hutchins, E., and Klausen, T. (2000) Distributed cognition in an airline cockpit: Cognition and communication at work. In: Cognition and communication at work, Y. Engström and D. Middleton, (Eds.). Cambridge University Press: New York, pp. 15-34.

Hutto, Daniel D. (2008). First communions: mimetic sharing without theory of mind. In: Jordan Zlatev, Timothy P. Racine, Chris Sinha, and Esa Itkonen (Eds.), The Shared Mind: Perspectives on intersubjectivity. Amsterdam/Philadelphia: John Benjamins, pp. 245-276.

Ihde, Don (1979). Technics and Praxis. Dordrecht and Boston: D. Reidel.

James, William (1899). Apperception. In: Talks to Teachers, Chap. 14, Cambridge, MA. [http://www.des.emory.edu/mfp/ttpreface.html]; downloaded $23^{\text {rd }}$ November 2011.

Juarrero, Alicia (1999). Dynamics in Action: Intentional behavior as a complex system. Cambridge, MA and London, UK: The MIT Press.

Keijzer, F. A. (2003). Self-steered self-organization. In: W. Tschacher, and J. -P. Dauwalder (Eds.), The Dynamical Systems Approach to Cognition. River Edge, NJ: World Scientific, pp. 243-259.

Kinsbourne, Marcel 2005. Imitation as entrainment: brain mechanisms and social consequences. In: Susan Hurley and Nick Chater, (Eds.), Perspectives on Imitation: From Neuroscience to Social Science. Volume 2: Imitation, human development, and culture. Cambridge, MA and London, England: The MIT Press, pp. 163-172.

Kirsh, David (1995a). The intelligent use of space. Artificial Intelligence 73: 31-68.

Kirsh, David (1995b). Complementary strategies: why we use our hands when we think. In: J. Moore and J. Fain Leman (Eds.), Proceedings of the Seventeenth Annual Conference of the Cognitive Science Society. Mahwah: NJ: Lawrence Erlbaum, pp. 212-217. 
Koffka, Kurt (1910). Über latente Einstellung. Bericht über den IV. Kongress für exper. Psychol. in Innsbruck.

Koffka, Kurt (1935). Principles of Gestalt Psychology. New York: Harcourt, Brace \& World.

Kravchenko, Alexander (2003). Sign, Meaning, Knowledge: An essay in the cognitive philosophy of language. Frankfurt am Main and New York: Peter Lang.

Kress, Gunther and Van Leeuwen, Theo (2001). Multimodal Discourse: The modes and media of contemporary communication. London: Arnold.

Kuhl, Patricia K. (2007). Is speech learning 'gated' by the social brain? Developmental Science 10(1): 110-120.

Kuhl, Patricia K. and Meltzoff, Andrew N. (1982). The bimodal perception of speech in infancy. Science 218: 1138-1141.

Kuhl, Patricia K. and Meltzoff, Andrew N. (1984). The intermodal representation of speech in infants. Infant Behavior and Development 7: 361-381.

Ladyman, James and Ross, Don (with Spurrett, David and Collier, John). (2007). Every Thing Must Go: Metaphysics naturalized. Oxford and New York: Oxford University Press.

Langacker, Ronald W. (1987). Foundations of Cognitive Grammar, Volume I: Theoretical prerequisites. Stanford, CA: Stanford University Press.

Laird, James D. (2007). Feelings: The perception of self. Oxford and New York: Oxford University Press.

LeDoux, Joseph E. (1996). The Emotional Brain: The mysterious underpinnings of emotional life. New York: Simon \& Schuster.

LeDoux, Joseph E. (2000). Emotion circuits in the brain. Annual Review of Neuroscience 23: 155-184.

Lefèbvre, Henri (2004 [1992]). Rhythmanalysis: Space, time and everyday life. Trans. Stuart Elden and Gerald Moore. London and New York: Continuum.

Lemke, Jay L. (2000a). Across the scales of time: artefacts, activities, and meanings in ecosocial systems. Mind, Culture, and Activity 7(4): 273-290.

Lemke, Jay L. (2000b). Material sign processes and emergent ecosocial organization. In: Peter Bøgh Andersen, Claus Emmeche, Niels Ole Finnemann, and Peder Voetmann Christiansen (Eds.), Downward Causation: Minds, bodies and matter. Aarhus: Aarhus University Press, pp. 181-213. 
Liberman, Alvin M. and Mattingly, Ignatius G. (1985). The motor theory of speech perception revised. Cognition 21: 1-36.

Lieberman, Philip (1967). Intonation, Perception and Language. Cambridge, MA: The MIT Press.

Linell, Per (2005). The Written Language Bias in Linguistics: Its nature, origin and transformations. Oxford: Routledge.

Linell, Per (2009). Rethinking Language, Mind, and World Dialogically: Interactional and contextual theories of human sense-making. Charlotte, NC: Information Age Publishing, Inc.

Love, Nigel (1990). The locus of languages in a redefined linguistics. In: Hayley G. Davis and Talbot J. Taylor (Eds.), Redefining Linguistics. London and New York: Routledge, pp. 53-117.

Love, Nigel (2007). Are languages digital codes?. Language Sciences 29: 690-709.

Luchins, A.S. (1942). Mechanization in problem solving: The effect of einstellung. Psychological Monograph 54, whole No. 248.

Luria, A. R. (1973). The Working Brain: An introduction to neuropsychology. Trans. Basil Haigh. London: Allen Lane.

Macherey, Pierre (2009). De Canguilheim à Foucault: La force des normes. Paris: La Fabrique Éditions.

MacNeilage, P. F., Rootes, T. P., and Chase, R. A. (1967). Speech production and perception in a patient with severe impairment of somesthetic perception and motor control. Journal of Speech and Hearing Research, 10: 449-467.

MacNeilage, MacNeilage, P. F., Studdert-Kennedy, M., and Lindblom, B. (1987). Primate handedness reconsidered. Behavioral and Brain Sciences 10: 247-303.

Malinowski, Bronislav (1936). (1936). The problem of meaning in primitive languages. In: CK. Ogden and I.A. Richards, The Meaning of Meaning, [1923], Supplement I. London: Kegan Paul, pp. 296-336.

Markoš, Anton (2002). Readers of the Book of Life: Contextualizing developmental evolutionary biology. Oxford and New York: Oxford University Press.

Maturana, Humberto R. (1970). Biology of Cognition. BCL Report 9.0. University of Illinois, Urbana.

Maturana, Humberto R. and Varela, Francisco J. (1980). Autopoesis and Cognition. Dordrecht: Reidel. 
Maturana, Humberto R. and Varela, Francisco J. (1987). The Tree of Knowledge: The biological roots of human understanding. Revised Edition. Boston: Shambala.

Mayr, Ernst (1976). Typological versus population thinking. In: Evolution and the Diversity of Life. Cambridge, MA: Harvard University Press, pp. 26-29.

Melser, Derek (2004). The Act of Thinking. Cambridge MA: The MIT Press.

Melser, Derek (2009). Verbal communication: from pedagogy to make-believe. Prepublication draft of paper in Language Sciences 31(5), Sept 2009.

http://www.derekmelser.org/essays/essayverbal.html [Downloaded 8th January 2010].

Meltzoff, Andrew N. and Moore, M. Keith (1977). Imitation of facial and manual gestures by human neonates. Science 198: 75-78.

Mouilso, Emily, Glenberg, Arthur M., Havas, David, and Lindeman, Lisa M. (2007). Difference in action tendencies distinguish anger and sadness after comprehension of emotional sentences. In: D. S. McNamara and J. G. Trafton (Eds.), Proceedings of the 29th Annual Cognitive Science Society. Austin, TX: Cognitive Science Society, pp. 1325-1330.

Noë, Alva (2004). Action in Perception. Cambridge, MA and London, England: The MIT Press.

O'Regan, J. Kevin and Noë, Alva (2001). A sensorimotor account of vision and visual consciousness. Behavioral and Brain Sciences 24: 939-1031.

Pattee, Howard H. (2000). Causation, control and the evolution of complexity. In: Peter Bøgh Andersen, Claus Emmeche, Niels Ole Finnemann, and Voetmann Peder Christiansen (Eds.), Downward Causation. Aarhus: Aarhus University Press, pp. 63-77.

Pattee, Howard H. (2001). The physics of symbols: bridging the epistemic cut. Biosystems 60: $5-21$.

Port, Robert (2007). The graphical basis of phones and phonemes. In: Ocke-Schwen and Murray J. Munro (Eds.), Language Experience in Second language Speech Learning: In honor of James Emil Flege. Amsterdam/New York: John Benjamins, pp. 349-365.

Port, Robert (2008). All is prosody: phones and phonemes are the ghosts of letters. Key Note Address for Prosody 2008, Campinas, Brazil, May 2008. To appear in the conference proceedings. [http://www.cs.indiana.edu/\%7Eport/HDphonol/Port.Prosody2008.keynote.pdf] Downloaded $27^{\text {th }}$ September 2010.

Port, Robert F. (2010). Language as a social institution: why phonemes and words do not live in the brain. Ecological Psychology 22: 304-326. 
Rączaszek, J., Tuller, B., Shapiro, L. P., Case, P., and Kelso, S. (1999). Categorization of ambiguous sentences as a function of a changing prosodic parameter: a dynamical approach. Journal of Psycholinguistic Research 28(4): 367-393.

Reed, Edward S. (1996a). Encountering the World: Toward an ecological psychology. New York and London: Oxford University Press.

Reed, Edward S. (1996b). The Necessity of Experience. New Haven: Yale University Press.

Rizzolatti, G., Fadiga L., Gallese V., and Fogassi L. (1996). Premotor cortex and the recognition of motor actions. Cognitive Brain Research 3: 131-141.

Rizzolatti, G. and Arbib, M. (1998). Language within our grasp. Trends in Neurosciences 21: 188-194.

Rosen, R. (1985). Anticipatory Systems: Philosophical, mathematical and methodological foundations. Oxford: Pergamon.

Ross, Don (2007). H. sapiens as ecologically special: what does language contribute?. Language Sciences 29: 710-731.

Salthe, Stanley N. (2011). Naturalizing Information. Information 2: 417-425. doi:10.3390/info2030417; ISSN 2078-2489; www.mdpi.com/journal/information.

Sancier, M., and Fowler, C. (1997). Gestural drift in a bilingual speaker of Brazilian Portuguese. Journal of Phonetics 25: 421-436.

Sander, Louis (1977). The regulation of exchange in the infant-character system and some aspects of the context-content relationship. In: M. Lewis and L. Rosenblum, (Eds.), Interaction, Conversation, and the Development of Language. New York: Wiley, pp. 133156.

Saussure, Ferdinand de (1993). Eisuke Komatsu (Ed.), Cours de Linguistique Générale: Premier et troisième cours d'après les notes de Reidlinger et Constantin. [Cours III, I ̀̀re partie: 1910-1911]. Collection Recherches Université Gaskushuin n ${ }^{\circ} 24$. Tokyo: Université Gakushuin.

Savage-Rumbaugh, Sue (2011). Human language - human consciousness.

[http://onthehuman.org/2011/01/human-language-human-consciousness/]; On the Human: a project of the National Humanities Center.

Scheflen, Albert E. (with Ashcraft, Norman). (1976). Human Territories: How we behave in space-time. Englewood Cliffs, NJ: Prentice-Hall, Inc.

Schögler, Ben and Trevarthen, Colwyn (2007). To sing and dance together: from infants to jazz. In: Stein Bråten (Ed.), On Being Moved: From mirror neurons to empathy. Amsterdam/Philadelphia: John Benjamins, pp. 281-302. 
Schrödinger, Erwin (1935). Die gegenwärtige Situation in der Quantenmechanik, Naturwissenschaften 23: 807-812; 823-828; 844-849. [English translation: 'The present situation in quantum mechanics: a translation of Schrödinger's "Cat Paradox Paper", originally published in Proceedings of the American Philosophical Society, 124, 323-38. [And then appeared as Section I.11 of Part I of Quantum Theory and Measurement (J.A. Wheeler and W.H. Zurek, Eds.). Princeton University Press, New Jersey 1983). [http://www.tu-harburg.de/rzt/rzt/it/QM/cat.html, downloaded $16^{\text {th }}$ June 2011]

Shankweiler, Donald, Strange, Winifred, and Verbrugge, Robert (1977). Speech and the problem of perceptual constancy. In: Robert Shaw and John Bransford (Eds.), Perceiving, Acting, and Knowing: Toward an Ecological Psychology. Hillsdale, NJ: Erlbaum, pp. 315346.

Simondon, Gilbert (2010). Communication et Information: Cours et conférences. Ed. Nathalie Simondon. Chatou: Les Éditions de la Transparence.

Stark, Rachel E., Rose, Susan N., and McLagen, Margaret (1974). Features of infant sounds: the first eight weeks of life. Journal of Child Language 2: 205-221.

Steels, Luc (2006). Semiotic dynamics for embodied agents. IEEE Intelligent Systems 21(3): 32-38. doi:10.1109/MIS.2006.58.

Steffensen, S.V. (2009). Language, languaging, and the extended mind hypothesis. Pragmatics \& Cognition 17(3): 677-698.

Steffensen, Sune V., Thibault, Paul J. and Cowley, Stephen J. (2010). Living in the social meshwork: the case of health interaction. In: Stephen Cowley, João C. Major, Sune V. Steffensen and Alfredo Dinis (Eds.), Signifying Bodies: Biosemiosis, interaction and health. Braga: The Faculty of Philosophy of Braga Portuguese Catholic University, pp. 207-244.

Stern, Daniel N. (1977). The First Relationship. Cambridge, MA: Harvard University Press.

Stern, Daniel N. (1984). Affect attunement. In: J. D. Call, E. Galensch, and R. L. Tyson, (Eds.), Frontiers of Infant Psychiatry, Volume 2. New York: Basic Books, pp. 3-13.

Stern, Daniel N. (2004). The Present Moment in Psychotherapy and Everyday Life. New York: W. W. Norton.

Stevens, Kenneth N. 1989. On the quantal nature of speech. Journal of Phonetics 17: 3-45.

Stuart, Susan and Thibault, Paul J. Forthcoming. Enkinaesthetic polyphony as the underpinning for first-order languaging.

Studdert-Kennedy, Michael and Goldstein, Louis (2003). Launching language: the gestural original of discrete infinity. In: M.H. Christiansen and S. Kirby, (Eds.), Language Evolution: The states of the art. Oxford University Press, pp. 235-255. 
Swenson, R., and Turvey, M. T. (1991). Thermodynamic reasons for perception-action cycles. Ecological Psychology 3: 317-348.

Thibault, Paul J. (1994). Text and/or context?. State-of-the-Art article. In: The Semiotic Review of Books (Toronto) 4(1) (May 1994): 10-12.

Thibault, Paul J. (1997). Re-reading Saussure: The dynamics of signs in social life. London and New York: Routledge.

Thibault, Paul J. (2004a). Brain, Mind, and the Signifying Body: An ecosocial semiotic theory. Foreword by M. A. K. Halliday. London and New York: Continuum.

Thibault, Paul J. (2004b). Agency and Consciousness in Discourse: Self-other dynamics as a complex system. London and New York: Continuum.

Thibault, Paul J. (2005a). What kind of minded being has language: Anticipatory dynamics, arguability, and agency in a normatively and recursively self-transforming learning system, Part 1. Linguistics and the Human Sciences 1(2): 261-335.

Thibault, Paul J. (2005b). What kind of minded being has language: Anticipatory dynamics, arguability, and agency in a normatively and recursively self-transforming learning system, Part 2. Linguistics and the Human Sciences 1(3): 355-401.

Thibault, Paul J. (2005c). The interpersonal gateway to the meaning of mind: unifying the inter- and intraorganism perspectives on language. In: Ruqaiya Hasan, Christian Matthiessen, and Jonathan J. Webster (Eds.), Continuing Discourse on Language: A Functional Perspective, Vol. 1. A volume presented to Michael Halliday on the occasion of his $80^{\text {th }}$ birthday at the International Systemic Functional Linguistics Congress, Sydney, July 2005. London and Oakville, CT: Equinox, pp. 117-156.

Thibault, Paul J. (2008). Face-to-face communication and body language. In: Karlfried Knapp and Gerd Antos (Eds.), Handbooks of Applied Linguistics (HAL) Linguistics for ProblemSolving: Perspectives on Communication Competence, Language and Communication Problems, and Practical Solutions. Volume 2: Interpersonal Communication. Gerd Antos \& Eija Ventola (eds.). Berlin. Mouton, pp. 285-330.

Thibault, Paul J. (2011). First-order languaging dynamics and second-order language: the distributed language view. Ecological Psychology 23(3): 210-245. To link to this article: http://dx.doi.org/10.1080/10407413.2011.591274

Trager, George L. (1958). Paralanguage: A first approximation. Studies in Linguistics 13(1): $1-12$.

Trevarthen, Colwyn (1992). An infant's motives for speaking and thinking in the culture. In: Astri Heen Wold (Ed.), The Dialogical Alternative: Towards a theory of language and mind. Oslo: Scandinavian University Press.), pp. 99-137. 
Trevarthen, Colwyn (1998). The concept and foundations of infant intersubjectivity. In: Stein Bråten (Ed.), Intersubjective Communication and Emotion in Early Ontogeny. Cambridge: Cambridge University Press, pp. 15-46.

Turvey, M.T. (1977). Preliminaries to a theory of action with reference to vision. In: R. Shaw and J. Bransford (Eds.), Perceiving, Acting and Knowing: Toward an ecological psychology. Hillsdale, NJ: Lawrence Erlbaum Associates, pp. 211-265.

Turvey, M. T., and Shaw, R. E. (1995). Toward an ecological physics and a physical psychology. In: R. Solso and D. Massaro (Eds.), The Science of Mind: 2001 and beyond. New York: Oxford University Press, pp. 144-172.

Vallée-Tourangeau, Frédéric, Euden, Gemma and Hearn, Vanessa (2011). Einstellung defused: Interactivity and mental Set. Quarterly Journal of Experimental Psychology 64(10): 1889-1895.

Van Orden, Guy C. and Holden, John G. (2002). Intentional contents and self-control. Ecological Psychology 14(1-2): 87-109.

Van Orden, G.C., Moreno, M.A., and Holden, J.G., (2003). A proper metaphysics for cognitive performance. Nonlinear Dynamics, Psychology, and Life Sciences 7: 49-60.

Van Orden, G.C., Holden J.G., and Turvey, M.T. (2005). Human cognition and 1/f scaling. Journal of Experimental Psychology: General 134: 117-123.

Van Orden, G.C., Kello, C.T., and Holden, J.G. In press. Situated behavior and the place of measurement in psychological theory. Ecological Psychology.

Verbrugge, Robert R. (1977). Resemblances in language and perception. In: Robert Shaw and John Bransford (Eds.), Perceiving, Acting, and Knowing: Toward an ecological psychology. Hillsdale, NJ: Lawrence Erlbaum, pp. 365-389.

Verbrugge, Robert R. (1980). Transformations in knowing: a realist view of metaphor. In: R. P. Honeck and R. R. Hoffman (Eds.), Cognitive and Figurative Language. Hillsdale, NJ: Lawrence Erlbaum, pp. 87-125.

Verbrugge, Robert R. (1985). Language and event perception: Steps toward a synthesis. In: W. H. Warren, Jr. and R. E. Shaw (Eds.), Persistence and Change. Hillsdale, NJ: Lawrence Erlbaum, pp. 157-194.

Vihman, Marilyn M. (1996). Phonological Development: The origins of language in the child. Cambridge, MA: Blackwell.

Von Uexküll, J. 1928. Theoretische Biologie. Frankfurt am Main: Suhrkamp.

Warren, William H. Jr. and Verbrugge, Robert R. (1981). Auditory information for breaking and bouncing events: a case study in ecological acoustics. Haskins Laboratories: Status 
Report on Speech Research SR-67/68.

Werner, Heinz and Kaplan, Bernard (1984 [1963]). Symbol Formation: An organismicdevelopmental approach to the psychology of language. Hillsdale, NJ: Lawrence Erlbaum.

Wheeler, Michael (2005). Reconstructing the Cognitive World: The next step. Cambridge, MA and London, England: The MIT Press.

Wilson, R. A., and Clark, A. (2009). How to situate cognition: Letting nature take its course. In: P. Robbins and M. Aydede (Eds.), The Cambridge Handbook of Situated Cognition. Cambridge: Cambridge University Press, pp. 55-77.

Zlatev, Jordan (2008). The co-evolution of intersubjectivity and bodily mimesis. In: Jordan Zlatev, Timothy P. Racine, Chris Sinha, and Esa Itkonen (Eds.), The Shared Mind:

Perspectives on intersubjectivity. Amsterdam/Philadelphia: John Benjamins, pp. 215-244. 